\section{EL MARCO REGULATORIO EN EL CONTEXTO DE LA GESTIÓN EMPRESARIALISTA Y LA MERCANTILIZACIÓN DEL DESARROLLO URBANO DEL GRAN SANTIAGO, CHILE}

Magdalena Vicuña del Río

\section{Resumen}

En este artículo se analiza el camino a través del cual la agenda neoliberal ha sido aplicada en el desarrollo urbano del Gran Santiago, y la forma en que la ciudad se ha modificado a medida que los cambios políticos y económicos del país se han ido manifestando en su marco regulatorio. Para ello se han recopilado y analizado los principales instrumentos del urbanismo reglamentario y operacional que han determinado la actividad inmobiliaria en el Gran Santiago a partir de la década de 1960. Se discute cómo se ha desarrollado el cambio de enfoque desde lo que Harvey ha llamado el Estado "gerencialista" de la década de 1960, a las formas de un Estado "empresarialista"

\section{THE REGULATORY FRAMEWORK WITHIN THE CONTEXT OF THE BUSINESS ADMINISTRATION AND THE COMMODIFICATION OF URBAN DEVELOPMENT IN GREATER SANTIAGO, CHILE ${ }^{1}$}

\author{
Magdalena Vicuña del Río
}

\section{Abstract}

This paper analyzes the implementation of the neoliberal agenda in the urban development of Greater Santiago and the way the city has been modified as the result of the impact of political and economic changes on its regulatory framework. To do so, this research compiles and analyzes regulatory and operational urban planning instruments that have defined the real estate activity in Greater Santiago since the 1960s. Likewise, this contribution discusses the switch from the "managerial" State proposed by Harvey in the 1960s to the "entrepreneurial" State that emerged during the 
surgidas a partir de las décadas de 1970 y 1980, y que hoy se manifiestan en una suerte de hibridismo de la neoliberalización.

\section{PALABRAS CLAVE: NEOLIBERALISMO, DESARROLLO URBANO, LEGISLACIÓN Y PLANIFICACIÓN URBANA, SANTIAGO DE CHILE.}

Fecha de recepción: 31-10-2012

Fecha de aceptación: 13-06-2013

1 Proyecto FONDECYT No 1110387, "Santiago de Chile: de la ciudad de los negocios, al negocio de las ciudades".

2 Chile. Arquitecta, Pontificia Universidad Católica de Chile (1999). Master in Community Planning, University of Maryland, Estados Unidos (2004). Candidata a Doctor en Arquitectura y Estudios Urbanos, PUC. Docente e investigadora de la Facultad de Arquitectura, Diseño y Estudios Urbanos, Pontificia Universidad Católica de Chile. Correo electrónico: mvicunad@uc.cl. 1970s and 1980s. Today, these two approaches act as a sort of hybrid neoliberalism.

\section{KEYWORDS: NEOLIBERALISM, \\ URBAN \\ DEVELOPMENT, URBAN LEGISLATION， URBAN PLANNING, SANTIAGO DE CHILE.}

\author{
Received: 31-10-2012 \\ Accepted: 13-06-2013
}

1 Fondecyt project 1110387 “Santiago de Chile: from the city of business to the business of cities".

2 Chile. Architect, Pontifical Catholic University of Chile (1999). MSc in Community Planning, University of Maryland, United States (2004). PhD candidate in Architecture and Urban Studies, Pontifical Catholic University of Chile. Professor and Researcher, Faculty of Architecture, Design and Urban Studies, Pontifical Catholic University of Chile. Email: mvicunad@uc.cl 


\section{Introducción}

El fenómeno de la "mercantilización de la dinámica urbana" hoy se ha impuesto en casi todo el mundo y constituye un rasgo propio de la urbanización capitalista. En aquellas áreas con factores que propician su plusvalía - localización adecuada o normativa flexible-, la inversión inmobiliaria se ha intensificado como nunca antes. Entre tales condiciones se encuentran la liberalización económica y la desregulación urbana, propias del modelo neocapitalista que hoy prima en el panorama mundial de ciudades.

El siguiente artículo constituye un análisis de dos procesos: (1) el camino a través del cual la agenda neoliberal ha sido aplicada en el urbanismo reglamentario y operacional de Santiago de Chile; y (2) la forma en que dicho camino ha mutado en la medida en que los cambios políticos y económicos del país se han cristalizado en el marco regulatorio de la ciudad. Es sabido que la normativa urbana determina - junto a otros factores, como la localización y las externalidades- el valor y la rentabilidad del suelo. El marco institucional tiene un rol fundamental en la ciudad capitalista, ya que la regulación urbana (o, en su defecto, la desregulación) y el comportamiento del sector inmobiliario están estrechamente relacionados. Esta problemática se plantea desde la perspectiva de Jonathan Barnett, ${ }^{3}$ quien señala que son los mecanismos de la zonificación, sus respectivos códigos urbanos y el trazado vial, los que proveen las claves fundamentales para la producción de ciudad. En efecto, tanto las normas urbanísticas como los instrumentos de planificación territorial son portadores de un modelo de ciudad, patrón que ciertamente responde a los modelos político-económicos imperantes y que, por tanto, refleja el proyecto político y social de la sociedad.

De esta manera, se discute cómo se ha desarrollado el cambio de enfoque desde lo que Harvey ha denominado el Estado "gerencialista", a unas formas de Estado "empresarialista", ${ }^{4}$ las cuales se manifiestan en la regulación urbana del Gran Santiago y en su relación con el incremento de la inversión inmobiliaria. Por último, se demuestra que en el caso del Gran Santiago, como producto de la historia política y económica del país, actualmente conviven ambas formas de planificación, la "gerencialista" y la "empresarialista".

En el artículo "Cities and the geographies of 'actually existing neoliberalism", Neil Brenner y Nick Theodore definen el término "neoliberalismo realmente existente", el cual implica la consideración de las interacciones dependientes de la trayectoria específica de escenarios regulatorios heredados

3 Barnett, 1982

4 Harvey, 1989. 
y proyectos emergentes de reformas neoliberales orientadas al mercado. Por tanto, este trabajo se enfoca en la descripción y análisis de la trayectoria de las transformaciones espaciales e institucionales del urbanismo neoliberal chileno, específicamente en el Gran Santiago, y sus tendencias particulares y específicas que definen el desarrollo de esta ciudad como coyuntura urbana específica.

Brenner y Theodore plantean que existe un "patrón prevaleciente de reestructuración regulatoria, que está tomando cuerpo a lo largo de un escenario institucional irregular y en el contexto de procesos político-económicos que co-evolucionan". ${ }^{5}$ En este sentido, es posible destacar tres fenómenos propios del desarrollo inmobiliario en el Gran Santiago.

Primero, se avanza hacia un modelo horizontal de relación entre los organismos públicos y el sector privado. En el contexto del modelo preponderante de Estado empresarialista, se ha revalorizado el papel del mercado tanto en la regulación de la actividad inmobiliaria como en la participación consensuada de los principales actores involucrados en los procesos de producción de ciudad.

Segundo, es posible observar ciertos ajustes técnico-urbanísticos en la escala local de administración. Específicamente, aquellas comunas que han presentado una importante actividad de renovación urbana y que además cuentan con recursos

Brenner y Theodore, 2002, p. 2. municipales demuestran límites al proyecto neoliberal, los cuales se han manifestado como una reacción tardía a procesos de inversión inmobiliaria iniciados en la década de 1990 y que han cobrado fuerza a inicios de la década del 2000.

En tercer lugar, desde que se impuso el modelo neoliberal y con la evolución hacia nuevos contextos sociopolíticos, es posible constatar que, en el caso del Gran Santiago, el mencionado modelo "empresarialista" presenta matices que lo acercan a una forma de tipo híbrida. ${ }^{6}$ Consecuentemente, se observan ciertas discordancias y contradicciones que son parte del modelo heredado de planificación centralista y una seguidilla de ajustes a los instrumentos de planificación urbana que responden al contexto neoliberal imperante.

Tanto Theodore, Peck y Brenner, como Harvey, plantean que el neoliberalismo y la evolución hacia el modelo empresarialista son procesos multiescalares y multidireccionales y por tanto deben ser examinados a nivel del barrio, la ciudad central y los suburbios, la región metropolitana y la nación. El enfoque de este artículo está en las escalas metropolitana y comunal, y en la relación entre los mecanismos de legislación y planificación urbana y el auge de la actividad inmobiliaria durante las últimas décadas. Nos referiremos al Gran Santiago como el territorio correspondiente a las 52

6 Theodore, Peck y Brenner, 2009. 
comunas que conforman la Región Metropolitana de Santiago. Como se explicará más adelante, en el año 2006 se amplió el área normada por el Plan Regulador Metropolitano de Santiago, para incorporar las provincias de Melipilla y Talagante, extendiéndose así a toda la región (Figura 1).

\section{Marco conceptual}

Hace poco más de una década, Brenner y Theodore definieron el término "neoliberalismo realmente existente". De acuerdo a estos autores, mientras el neoliberalismo corresponde a un proyecto ideológico, una utopía que establece leyes inmutables, el neoliberalismo realmente existente no es puro, ya que implica la consideración de las interacciones dependientes de las contextualizaciones específicas de escenarios regulatorios heredados y proyectos emergentes de reformas neoliberales orientadas al mercado. De esta manera, señalan que existiría una distancia entre el proyecto disciplinario del neoliberalismo y sus operaciones políticas y efectos sociales.

Brenner y Theodore plantean que analizar el neoliberalismo desde sus definiciones presenta significativas limitaciones analíticas, por cuanto "la ideología neoliberal sistemáticamente distorsiona

7 Brennery Theodore, 2002. los verdaderos efectos que tienen las políticas neoliberales en las estructuras macroinstitucionales y trayectorias evolutivas del capitalismo." En efecto, estos autores señalan que la imposición global del modelo neoliberal ha sido desigual en términos sociales y geográficos, y sus formas institucionales y consecuencias sociopolíticas han variado significativamente a través de diversas escalas espaciales. La regulación capitalista es mediada políticamente e internaliza las relaciones sociales en conflicto, propias de su contexto; por tanto, cada ciclo de desarrollo capitalista está asociado con un paisaje geográfico e históricamente específico, en el cual algunos lugares, territorios y escalas son sistemáticamente privilegiadas por sobre otras, como sitios de acumulación de capital. ${ }^{9}$ El neoliberalismo realmente existente es entonces de carácter multiescalar, multidireccional, geográficamente variable e interconectado. ${ }^{10}$

Consecuentemente, un adecuado entendimiento de los procesos contemporáneos de neoliberalización no sólo requiere captar sus fundamentos político-ideológicos, sino que también una búsqueda sistemática de sus propiedades emergentes y formas institucionales, efectos sociopolíticos y múltiples contradicciones. ${ }^{11}$ Esta condición es la que Theodore, Peck y Brenner llaman de hibridismo,

8 Theodore, Peck y Brenner, 2009, p. 4.

9 Brennery Theodore, 2002, p. 353.

10 Theodore, Peck y Brenner, 2009.

11 Ibíd, p. 6. 


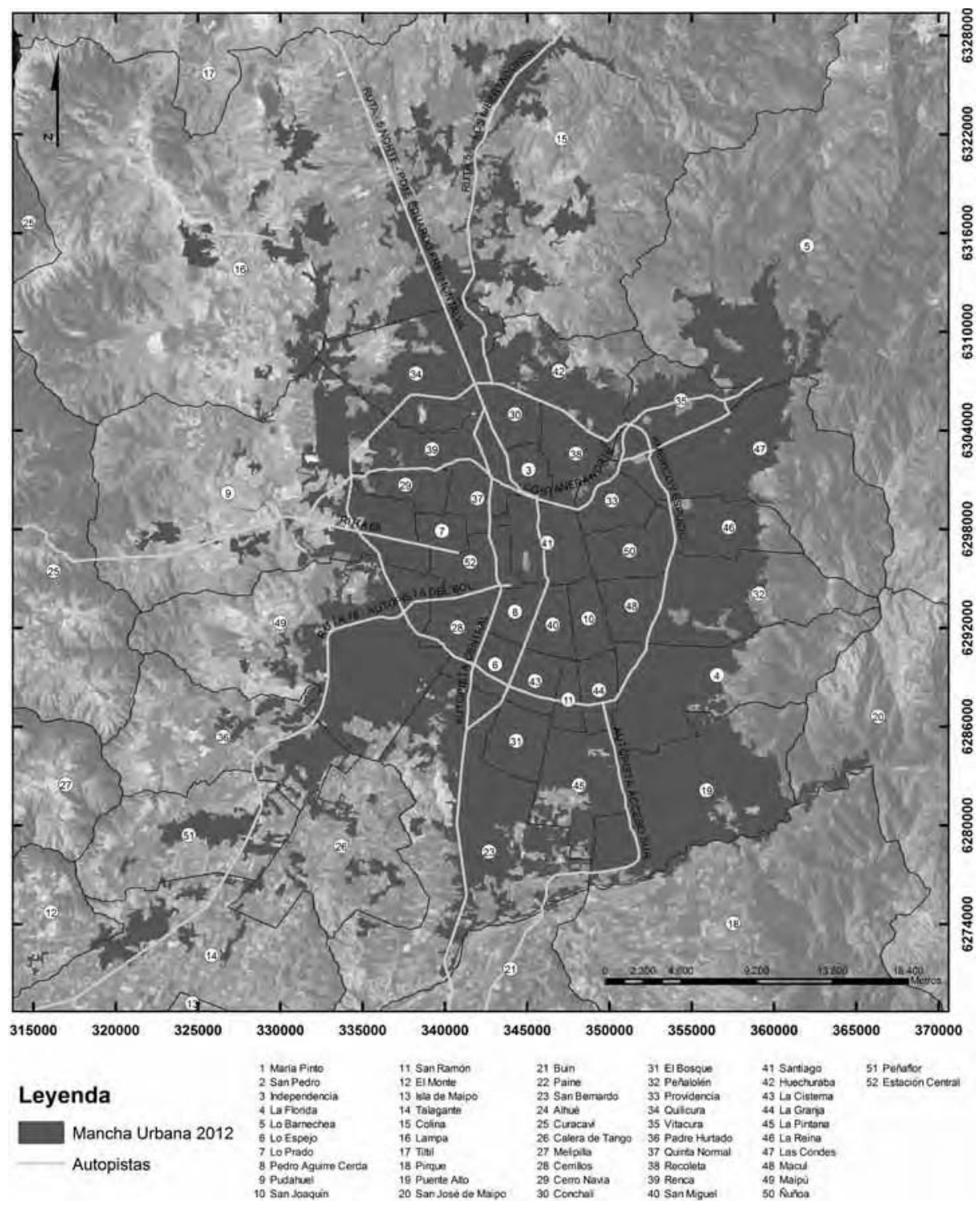

FIGURA 1. GRAN

SANTIAGO, MANCHA

URBANA Y RED

DE AUTOPISTAS

CONCESIONADAS.

Fuente: Xlab, Instituto de Estudios Urbanos y Territoriales UC.

$\frac{0}{6}$

웅

商

啇 
en la cual el neoliberalismo tiende a concretarse en "una suerte de relación 'parasitaria' con otras formas de Estado o de sociedad (neoconservadurismo, autoritarismo, social-democracia, etc.)". ${ }^{12}$

El neoliberalismo realmente existente debe entenderse como un proceso, en la medida que las formas contemporáneas del neoliberalismo son expresiones de una "destrucción creativa" del espacio político-económico en diversas escalas geográficas. Dicha destrucción creativa es planteada como una forma útil para describir las trayectorias de las transformaciones espaciales e institucionales del neoliberalismo. ${ }^{13}$ Así, la neoliberalización se presenta como un proceso reactivo, con momentos destructivos y creativos que, aunque puedan ser distintos en términos analíticos, están dialécticamente relacionados. ${ }^{14}$

El neoliberalismo realmente existente consiste entonces en un proceso de búsqueda que se desarrolla en base a prueba y error. ${ }^{15}$ Por lo tanto, las formas y caminos de la urbanización neoliberal deben considerarse como estrategias reestructuradoras profundamente contradictorias que están desestabilizando significativamente los escenarios heredados de gobernanza urbana y regulación económica.

12 Ibíd, p. 4.

13 Brennery Theodore, 2002.

14 Theodore, Peck y Brenner, 2009, p. 7.

15 Ibíd, p. 10.
Theodore, Peck y Brenner plantean que las grandes ciudades constituyen laboratorios para diversos experimentos de políticas neoliberales. ${ }^{16}$ Debido a que la ciudad es el lugar donde fracasarían las políticas neoliberales y donde se daría la resistencia a los programas de reestructuración urbana, constituye un punto de referencia para comprender algunos límites, contradicciones y mutaciones del proyecto neoliberal. ${ }^{17}$

Un par de décadas antes a la definición del "neoliberalismo realmente existente", David Harvey planteó que la aproximación gerencialista de los estados, característica de la década de 1960, estaba dando paso consistentemente a formas de acción empresarial. ${ }^{18}$ Harvey indaga en las razones e implicancias de esa transformación durante las décadas de 1970 y 1980, la cual se estaba concretando en lo que denomina "estado empresarialista". Destaca que dicha transformación cruzaba fronteras nacionales e incluso partidos e ideologías políticas y que, si bien no se había terminado de concretar, respondía a las dificultades que asediaron a las economías capitalistas desde la recesión de 1973.

Según lo indicado por Harvey, el nuevo empresarialismo presenta ciertas condiciones nucleares: (1)

Ibíd, p. 8.

Ibíd, p. 7.

Harvey, 1989, p. 4. 
la asociación público-privada, en la cual las formas tradicionales de emprendimiento local se integran con el uso de poderes del gobierno local, con la finalidad de atraer recursos externos de financiamiento, nuevas inversiones directas y fuentes de empleo; (2) en oposición al desarrollo planificado, la asociación público-privada es empresarialista en cuanto es especulativa en su diseño y ejecución y por tanto obstaculizada por las dificultades y peligros asociados a la especulación. En muchas instancias esto significa que el sector público asume el riesgo y el sector privado capta los beneficios de dichas acciones especulativas; y (3) el empresarialismo se enfoca en la economía política del lugar más que en la del territorio. ${ }^{19}$

En efecto, el empresarialismo urbano fomenta el desarrollo de aquellas actividades y emprendimientos que tienen la capacidad localizada más fuerte para aumentar los valores de la propiedad, la base impositiva, la circulación local de ingresos y el crecimiento del empleo. ${ }^{20}$ Sin embargo, tanto el empresarialismo urbano como la competencia inter urbana son susceptibles de abrir camino a patrones de desarrollo desigual. ${ }^{21}$ Por tanto, el desplazamiento hacia el empresarialismo en la gobernanza urbana debe ser examinado en diversas escalas espaciales: barrios y comunidades locales,

\footnotetext{
19 lbíd, p. 7.

20 Ibíd, p. 13

21 Ibíd, p. 5
}

188 revista invi № 78 / Agosto 2013 / Volumen № 28: 181-219 ciudad central y suburbio, región metropolitana, región, nación estado, entre otras.

En el contexto chileno, Sierra hace la distinción entre una regulación urbana con sentido "vertical" y otra con sentido "horizontal". La primera correspondería a las normas impuestas por los organismos públicos, no acordadas con las personas y de carácter imperativo y de control. Según Sierra, la zonificación correspondería a una regulación urbana vertical. La segunda se basa en dispositivos destinados a incentivar acuerdos entre las personas, tales como mecanismos tributarios, derechos de impacto, de densificación y, en general, derechos inmobiliarios transferibles. ${ }^{22}$

Sierra sostiene que en Chile la regulación urbana vertical es pesadamente centralista y confusa en términos institucionales. Plantea que el contexto institucional chileno constituye una "selva" normativa debido a la confusión del esquema de potestades, en el cual prima la potestad administrativa, esto es, la del gobierno central. Por tanto, dicha confusión "genera un ambiente institucional proclive a las regulaciones verticales, que se imponen a los ciudadanos, y hostil a las horizontales, que les permitan negociar a los ciudadanos". ${ }^{23}$

\section{Sierra, 2006, p. 301.}

23 Ibíd, p. 326. 
Sin embargo, recientemente los investigadores López-Morales, Gasic y Meza demuestran que en el caso de la planificación comunal de Santiago estaríamos ante un modelo de "urbanismo pro-empresarial", en el cual la asociación público-privada es central en la toma de decisiones para el desarrollo urbano. Los autores abordan el modelo del "urbanismo pro-empresarial", propuesto por Harvey, para el análisis de los instrumentos de planificación comunal en el área central y pericentral de Santiago y su relación con la inversión inmobiliaria. Señalan que los ajustes técnico-urbanísticos implementados por los municipios están orientados a la atracción de capital requerido para producir renovación urbana a gran escala y por tanto son fundamentales para la producción neoliberal del espacio urbano. ${ }^{24}$

A partir de la revisión de 6 casos de estudio, los autores observan que la existencia del urbanismo pro-empresarial en Santiago comporta cinco factores: (1) una fragmentación de la planificación urbana comunal; (2) alianzas público-privadas que impulsan a los gobiernos locales a establecer vínculos directos y eficientes con el sector privado para la toma de decisiones; (3) una planificación y gestión de proyectos urbanos que promueven el desarrollo económico de lugares específicos, sustentadas en la posterior redistribución de los beneficios sociales al resto de la población; (4) la absorción por parte del municipio de los riesgos políticos a largo plazo, producto de la especulación con los beneficios obtenidos por las operaciones inmobiliarias y (5) el actual re-desarrollo intensificado en altura responde a lógicas de competencias entre comunas, más que a una coordinación racional del crecimiento urbano.

En efecto, estos autores concluyen que si bien la alianza público-privada no es condición necesaria para la renovación intensiva del suelo, sí lo es un estado de competencia intercomunal, la capacidad de los gobiernos locales pericentrales de relocalizar áreas de renovación urbana vía modificaciones normativas, y la generación deliberada de movilidad intra y extracomunal de capital inmobiliario.

El análisis del "neoliberalismo realmente existente" en el caso del Gran Santiago se operacionaliza en el presente artículo a través de: (1) la descripción y el análisis de la trayectoria de las transformaciones espaciales e institucionales del urbanismo neoliberal chileno, específicamente en el Gran Santiago, y sus tendencias de desarrollo particulares y específicas; (2) dicho análisis necesariamente considera tanto las formas híbridas como las contradicciones inherentes al neoliberalismo realmente existente; (3) la existencia de una forma de estado empresarialista y un urbanismo pro-empresarial, que en el caso del Gran Santiago se manifiestan en la fragmentación de la planificación urbana comunal y a través de asociaciones público-privadas con características específicas; (4) dichas características de

24 López Morales, Gasic y Meza, 2012, p. 78. 
la asociación público-privada estarían evidenciando un desplazamiento hacia un modelo horizontal en la toma de decisiones para la planificación del desarrollo urbano comunal e intercomunal.

\section{Metodología}

La metodología utilizada consistió primeramente en la construcción de un marco conceptual en relación a la discusión sobre el modelo neoliberal y sus implicancias en el desarrollo urbano. En segundo término, se realizó una revisión de la legislación urbanística chilena e instrumentos de planificación territorial del Gran Santiago en tres niveles de registro:

(1) Nivel nacional: Ley y Ordenanza General de Urbanismo y Construcciones. Las versiones revisadas de la Ley General son las de 1953 y 1976, así como el proyecto que modifica dicha ley en materia de planificación urbana. Las versiones de la Ordenanza General son las de 1949 y sus modificaciones y la de 1992.

A su vez, se revisaron reglamentos relacionados al ámbito del desarrollo urbano y de la vivienda económica formulados a partir de la década de 1960, entre los que se encuentran el Decreto con Fuerza de Ley $\mathrm{N}^{\circ} 2$, las Circulares de la División de Desarrollo Urbano del Ministerio de Vivienda y Urbanismo, la Ley de Concesiones y la Ley de Financiamiento Compartido, entre otras. Dentro de este nivel se encuentra también la revisión del Decreto Ley N³.516 y las Políticas Nacionales de Desarrollo Urbano de 1979 y 1985.

(2) Nivel intercomunal: planes reguladores intercomunales y metropolitanos en el Gran Santiago. En este nivel cobra importancia la definición del límite urbano y de densidades promedio para la ciudad y sus comunas. También son relevantes las propuestas de vialidad y transporte y su articulación con la implementación de otras políticas relacionadas, como la concesión de autopistas urbanas y las políticas habitacionales. En este nivel se encuentra el Plan Regulador Intercomunal de Santiago (1960), el Decreto N420 (1979) y el Plan Regulador Metropolitano de Santiago (1994) y sus sucesivas modificaciones (1997, 2003, 2006 y 2011).

(3) Nivel comunal: planes reguladores comunales, sus respectivas memorias explicativas y modificaciones. Se analizan en detalle los planes de las comunas de Santiago y Providencia.

Además, se revisaron fuentes secundarias en relación a estos instrumentos regulatorios. Por último, se llevó a cabo un análisis de proyectos específicos implementados durante los últimos años en la ciudad de Santiago. El levantamiento de los casos se realizó a partir de material fotográfico recolectado en terreno y de documentaciones como el Estudio de Impacto sobre el Sistema de Transportes (EISTU) del proyecto Costanera Center y los permisos 
de edificación de la Dirección de Obras Municipales de las comunas de Providencia y Santiago, entre otros.

Finalmente, se realizó un análisis interpretativo de dichos instrumentos legales y de planificación y su implementación en el caso del Gran Santiago. Todo ello, dentro del marco teórico del neoliberalismo existente, el urbanismo neoliberal y sus implicancias en el desarrollo y planificación de las grandes ciudades.

\section{De la planificación racionalista a la irrupción del neoliberalismo en la planificación del Gran Santiago: hacia un modelo "horizontal" de relación entre los organismos públicos y el sector privado}

Tras la Segunda Guerra Mundial, en gran parte del mundo occidental se impuso el modelo de la planeación comprensiva, cuyo propósito era la racionalización de la organización y el funcionamiento de las ciudades. En el caso de Santiago de Chile, la planificación urbana racionalista tuvo uno de sus más importantes exponentes en el Plan Regulador Intercomunal de Santiago (PRIS) de 1960, desarrollado por el Ministerio de Obras Públicas (MOP). El modelo de ciudad propuesto por el PRIS planteaba un límite para el crecimiento de Santiago, el cual separaba el área urbana de la rural. A través del mecanismo de la zonificación, en el PRIS se asignaban determinados usos de suelo que ordenaban y separaban las actividades, y se reservaban espacios para áreas verdes. El PRIS evidencia la provisión de nuevas centralidades y el significativo rol que el transporte y la planificación de la infraestructura vial tienen en este nuevo orden de Santiago. ${ }^{25}$ Gran parte de la vialidad estructurante y parte de los subcentros de equipamientos propuestos por el PRIS han sido implementados en el transcurso de las últimas tres décadas, lo que para algunos autores demuestra la importante presencia de este instrumento de planificación territorial en el desarrollo de Santiago. ${ }^{26}$

El PRIS es producto de lo que Harvey ha denominado el Estado "gerencialista". Responde a un modelo de planificación normativa y centralizada, a escala nacional y regional, que incluía la producción de bienes y servicios. En este modelo, el Estado no sólo planifica el desarrollo urbano, sino que también realiza inversión pública directa en

Ponce de León, 1996.

Poduje, 2006, p. 239. 
equipamientos, infraestructura y vivienda. En el caso de Santiago, la inversión en vivienda se implementó principalmente a través de dos entidades: la Corporación de Mejoramiento Urbano (CORMU, 1966-1975) y la Corporación de Vivienda (CORVI, 1953-1976), la cual puso en práctica proyectos de vivienda social que iban desde el apoyo a la autoconstrucción, a la realización de los edificios bloque conocidos como 1010 y 1020.

En este sentido, la planificación urbana de Santiago estaba en absoluta sintonía con el Plan Habitacional de 1959 y con la Ley General de Construcciones y Urbanización del país (aprobada en 1953). El PRIS entra en vigencia en forma paralela al Plan Habitacional Decreto Fuerza Ley, DFL No $2^{27}$ y su respectivo Reglamento para Viviendas Económicas, por lo que cobraba relevancia la zonificación de las áreas que podrían acoger las viviendas que accedían a dicho beneficio tributario. A la vez, el PRIS se articulaba con la Ley General de 1953, la que, en una modificación de 1961, planteó que "las Municipalidades en cuya comuna exista Plan Regulador podrán declarar zonas de construcción obligatoria

27 El DFL No 2 establecía beneficios tributarios para las viviendas económicas, de manera de incentivar la construcción de viviendas en el sector privado. Constituyó el instrumento básico que contenía las disposiciones del Plan Habitacional. Implicó transformar la Corporación de Vivienda en un organismo centralizado y autónomo, encargado del planeamiento, ejecución y administración del Programa Nacional de Viviendas (Aguirre, 1998, p. 25).

192 revista invi № 78 / Agosto 2013 / Volumen Nº 28: 181-219 y de remodelación, en la forma y condiciones que determine el Reglamento de este decreto con fuerza de ley" ${ }^{28}$ La remodelación de las áreas centrales ${ }^{29}$ hacía referencia a la concepción de que el déficit de vivienda se solucionaría a partir de la densificación. Por tanto, la densificación se lograba mediante la reconstrucción de áreas centrales en estado de deterioro, la renovación urbana y la reserva de terrenos para la construcción de viviendas económicas y de autoconstrucción en la periferia.

La zonificación del PRIS y los proyectos de vivienda implementados por las instituciones mencionadas corresponden al arquetipo de lo que Sierra ha denominado regulación "vertical", pues sus normas eran impuestas "desde arriba". ${ }^{30}$ En este modelo, los principales actores en la producción de ciudad serían el Estado a través del MOP, e instituciones públicas como la CORMU, la CORVI y posteriormente el MINVU.

Como hemos señalado, las reformas estructurales al modelo gerencialista adquirieron relevancia por primera vez a fines de la década de 1970 y constituyeron una respuesta política estratégica a dos

28 Artículo 8, Ley General sobre Construcciones y Urbanización de 1953.

29 Las áreas centrales se zonificaron dentro del área delimitada principalmente por la avenida Vicuña Mackenna por el oriente, Isabel Riquelme por el sur, General Velásquez por el poniente y el río Mapocho por el norte, incluyendo algunos sectores al norte del río, en lo que hoy corresponde a las comunas de Independencia y Recoleta.

30 Sierra, 2006, p. 302. 
fenómenos: la decreciente rentabilidad de las industrias de producción masiva y la crisis del Estado de Bienestar keynesiano. ${ }^{31}$ Con el golpe militar de 1973, dichas reformas neoliberales fueron drásticamente impuestas en Chile por un grupo de economistas formados en la Escuela de Chicago y se manifestaron en el gobierno de la ciudad a través del Decreto Supremo No 420 (1979), el cual modifica el PRIS, y el Decreto Ley No 3.516/80 (1980). Ambos instrumentos dieron inicio a la liberalización del desarrollo urbano.

En efecto, tal como sostienen Theodore, Peck y Brenner, "la ideología neoliberal se sustenta en la creencia de que los mercados abiertos, competitivos y 'no regulados', que no se encuentran sometidos a injerencias estatales ni a las acciones de colectivos sociales, representan el mecanismo óptimo para el desarrollo socioeconómico". 32 En consecuencia, apoyándose en el Decreto $\mathrm{N}^{0} 420$, los principios de liberalización y desregulación urbana mencionados por los autores reseñados se materializaron en Santiago en dos situaciones: la extensión del límite urbano y la liberalización de las responsabilidades del Estado respecto de la dotación de infraestructura y equipamiento urbano en las nuevas áreas de expansión metropolitana, responsabilidades que fueron entregadas al sector privado. Cabe agregar que, tal como comprueba

31 Theodore, Peck y Brenner, 2009, p. 2.

32 Ibíd.
Petermann ${ }^{33}$, la ciudad se había expandido considerablemente fuera del límite urbano impuesto por el PRIS en 1960, producto de la política habitacional estatal. Con la aplicación del Decreto No 420, se declaró como área de expansión urbana de Santiago una superficie de aproximadamente 60.000 hectáreas, equivalente a 160\% del área urbana.

Las normas para el área de expansión urbana de Santiago se categorizaban mediante tramos genéricos (Tabla 1), los cuales podían ser alterados automáticamente cuando se trataba de proyectos cuya superficie era mayor a 5 hectáreas, posibilitando condiciones para una mayor densidad. Por ejemplo, los proyectos de más de 5 hectáreas que se localizaran en sectores normados bajo las condiciones del tramo A, pasaban automáticamente a normarse bajo las condiciones del tramo $\mathrm{C}$, disminuyendo la subdivisión predial normada y aumentando así la densidad, constructibilidad y ocupación de suelo.

Los postulados de la Política Nacional de Desarrollo Urbano de 1979 orientaron la modificación del PRIS a través del Decreto $N^{\circ} 420$, y en parte se basaron en los argumentos del asesor del gobierno militar Arnold Harberger (economista de la Escuela de Chicago), quien sostenía que el suelo "no es un bien escaso". Harberger también planteaba que el límite urbano establecido por el PRIS era el causante del desequilibrio de los valores de suelo entre

33 Petermann, 2006. 


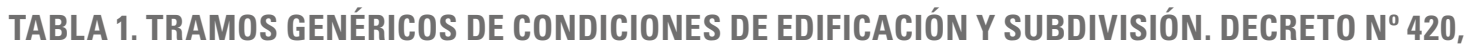
MINISTERIO DE VIVIENDA Y URBANISMO, 1979.

\begin{tabular}{lllll}
$\begin{array}{l}\text { Tramo } \\
\text { genérico }\end{array}$ & Densidad bruta (hab/ha) & $\begin{array}{l}\text { Coeficiente máx. de } \\
\text { constructibilidad }\end{array}$ & $\begin{array}{l}\text { Porcentaje máx. de } \\
\text { ocupación de suelo }\end{array}$ & $\begin{array}{l}\text { Superficie mínima } \\
\text { predial de m² }\end{array}$ \\
\multirow{2}{*}{ A } & 2,45 & 0,063 & $3,0 \%$ & 16.000 \\
& 4,90 & 0,045 & $4,5 \%$ & 8.000 \\
\hline \multirow{2}{*}{ B } & 4,90 & 0,045 & $4,5 \%$ & 8.000 \\
& 9,80 & 0,080 & $8,0 \%$ & 4.000 \\
\hline C & 9,80 & 0,080 & $8,0 \%$ & 4.000 \\
& 19,60 & 0,140 & $14,0 \%$ & 2.000 \\
\hline \multirow{2}{*}{ E } & 19,60 & 1,140 & $14,0 \%$ & 2.000 \\
& 49,00 & 0,300 & $30,0 \%$ & 800 \\
\hline \multirow{2}{*}{ F } & 49,00 & 0,300 & $30,0 \%$ & 800 \\
& 81,63 & 0,400 & $40,0 \%$ & 480 \\
\hline
\end{tabular}

Fuente: Elaboración propia con base en el Artículo 13, Título II, del Decreto Nº 420, Ministerio de Vivienda y Urbanismo, 1979.

el área urbana y el área rural, y que la supresión del límite "suavizaría la curva de distribución espacial de los valores de suelo". ${ }^{34}$

Coincidentemente, el Decreto $N^{\circ} 420$ señala que se buscaba lograr "una mayor flexibilidad en el crecimiento, estructuración y renovación urbana, aumentando la oferta de suelo potencialmente urbanizable". ${ }^{35}$ A su vez, el Ministerio de

34 Massone, 1996, p. 56.

35 Ministerio de Agricultura, 1979, p. 1.

194 revista invi № 78 / Agosto 2013 / Volumen N² 28: 181-219
Agricultura aprobó estas modificaciones, considerando que "las características de baja transparencia y acumulación de externalidades del mercado del suelo en el Área Metropolitana hacen necesario introducir un elemento corrector a través de la regulación del suelo del área mencionada, de manera de crear una mayor oferta potencial de suelo urbano que redunde en una estabilización y eventual equilibrio de este mercado, tanto en el área 
de expansión urbana, como al interior del área urbana propiamente tal". ${ }^{36}$ De esta manera, en los términos de Theodore, Peck y Brenner, ${ }^{37}$ el suelo se convertirá en una mercadería transable, confiándose así a "la mano invisible del mercado" la óptima asignación de recursos en la ciudad.

Por su parte, el Decreto Ley No 3.516, del Ministerio de Agricultura, estableció las normas de subdivisión de predios rústicos y su cambio de destino, permitiendo la subdivisión de suelo rural en predios de hasta $5.000 \mathrm{~m}^{2}$. Como consecuencia de la práctica extendida de la aplicación del Decreto $\mathrm{N}^{\circ}$ 3.516, la ciudad de Santiago se ha extendido a partir de un patrón denominado como "ciudad infiltrada", esto es, "una urbanización de baja densidad que rellena los intersticios entre la ciudad central y los asentamientos humanos de menor jerarquía que la rodean, cuya modalidad característica es el condominio cerrado y las parcelas de agrado, ocupados por habitantes de estratos sociales altos y medios altos, entre los que permanecen resabios de la antigua comunidad rural" ${ }^{38}$ La expansión urbana producto del Decreto Ley No 3.516 también ha sido denominada como "ciudad extraoficial", "ciudad informal dispersa" o "ciudad invisible", por cuanto implica la transformación de las áreas

36 Ministerio de Agricultura, 1979, p. 2.

37 Theodore, Peck y Brenner, 2009.

38 Naranjo, 2009b, p. 5. rurales del periurbano en zonas residenciales de muy baja densidad (2-4 viviendas/hectárea). ${ }^{39}$

En 1985 se ajustó la Política Nacional de Desarrollo Urbano de 1979. En el plano teórico cobraron valor aspectos como la calidad de vida, el patrimonio cultural, el medioambiente y la participación ciudadana. Como señala Massone, en este período también se valorizó la realización de exhaustivos diagnósticos para comprender la estructura urbana de la ciudad, así como la realización de una imagen objetivo que integrara dicho diagnóstico. ${ }^{40}$

Sin embargo, el ajuste de la Política Nacional de Desarrollo Urbano corrobora el rol del mercado como el principal gestor de ciudad, mientras se le asignaba al Estado la función de establecer las regulaciones mínimas para su desarrollo: “... corresponde al Estado, a través de la planificación y de las normativas urbanas, fijar las condiciones mínimas de diseño y conservación que sean necesarias y convenientes para que las urbanizaciones y edificaciones aseguren a los ciudadanos una habitabilidad satisfactoria del espacio urbano, tanto en su expresión de espacio público, como en las de los espacios prediales y edificados". ${ }^{4}$

\footnotetext{
39 lbíd.

40 Massone, 1996, p. 58.

41 Ministerio de Vivienda y Urbanismo (MINVU), 1985, p. 14.
} 
El ajuste a la política de 1985 proponía una zonificación de áreas consolidadas, áreas urbanizables y áreas especiales. En contraste con la política de 1979, en 1985 se planteó que las áreas urbanizables se dividirían en subáreas "de primera prioridad", "de segunda prioridad" y "de tercera prioridad", siendo las primeras las adyacentes a las áreas consolidadas. ${ }^{42}$

Ya a principios de la década de 1990, las consecuencias de la desregulación impulsada por el Decreto $N^{\circ} 420$ y el Decreto Ley No 3.516 eran evidentes, ya que el área urbanizable de la ciudad se amplió considerablemente ${ }^{43}$ y la expansión hacia la periferia se mantenía carente de infraestructura, equipamientos y servicios y con un alto consumo de suelo agrícola. ${ }^{44}$ Por otro lado, la política de vivienda social impulsada desde la década de 1960, consistente en la erradicación de asentamientos informales, también contribuiría a llevar el crecimiento de la ciudad hacia fuera del límite urbano, especialmente hacia la periferia sur.

De acuerdo con lo planteado por Theodore, Peck y Brenner, la ideología neoliberal no necesariamente coincide con la práctica política, lo que genera fallas de mercado generalizadas, especialmente en el contexto urbano. En el caso de Santiago, la aspiración hacia una eficiente

42 Ibíd, p. 9.

43 Al respecto véase Galetovic, 2006.

44 Naranjo, 2009a. asignación de recursos e inversiones en la ciudad se tradujo, en palabras de los autores, en "nuevas formas de polarización social, una grave agudización de las desigualdades en el desarrollo espacial, y diversas crisis al interior de las formas institucionalizadas de regulación y gobernanza estatal". ${ }^{45}$

Con el retorno a la democracia en 1990 y el retroceso relativo de las políticas neoliberales, el Ministerio de la Vivienda y Urbanismo intentó revertir esta situación, dando un giro en el principal instrumento de planificación de la ciudad. Con la aprobación del Plan Regulador Metropolitano de Santiago (PRMS) de 1994, se retomó gran parte de los planteamientos del PRIS de 1960, en un intento por volver a la planificación racionalista y rescatar aquella idea de ciudad contenida dentro de un límite y de un ordenamiento de las actividades a través de la zonificación, la vialidad estructurante y su articulación con subcentros de equipamientos.

La imagen objetivo que el PRMS planteaba para Santiago era la de una ciudad densa. En efecto, el PRMS fijó una densidad mínima para las áreas urbanizadas de 150 hab/ha, la cual estaba muy por encima de la densidad real del Gran Santiago, que era poco mayor de 96,5 hab/ha. ${ }^{46}$

45 Theodore, Peck y Brenner, 2009, p. 3

46 Poduje, 2006, p. 246. 
FIGURA 2. EVOLUCIÓN DEL LÍMITE PLANIFICADO Y MANCHA URBANA DE SANTIAGO, 1960-1994.

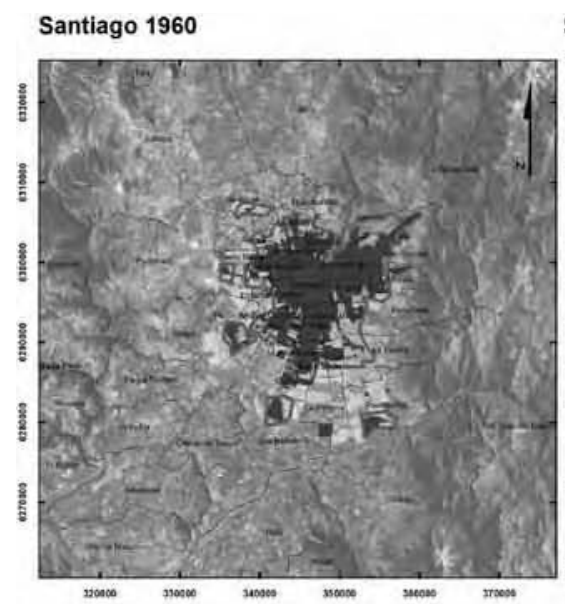

Santiago 1979

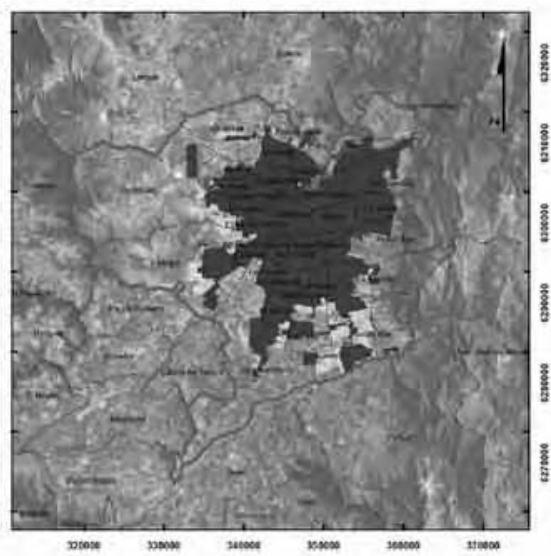

Santiago 1994

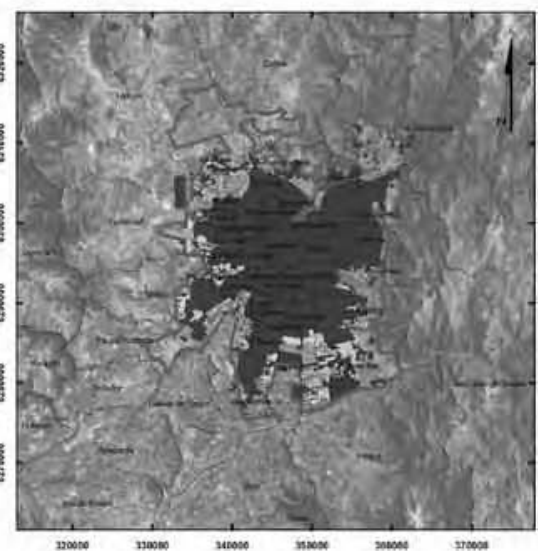

Leyenda

Mancha Urbana

Limite Urbano

Fuente: Xlab, Instituto de Estudios Urbanos y Territoriales UC.

Sin embargo, como ha documentado y comprobado Poduje, pese a la existencia del límite urbano impuesto por el PRMS, la ciudad continuó creciendo en extensión, sobrepasando dicho límite. Prontamente fue necesario modificar este instrumento normativo, ya que el mercado inmobiliario continuaba expandiéndose y extendiendo el área urbana. La actividad del sector inmobiliario resultó muy difícil de controlar, "sobre todo en los casos en que (...) ya se había impuesto la liberalización y la desregulación", ${ }^{47}$ esta última posibilitada, en el caso de Santiago, por los decretos $\mathrm{N}^{\circ}$ 420 y No 3516 y por la Ley General de Urbanismo y Construcciones de 1976. En otras palabras, aunque el PRMS así lo establecía, en la práctica se hizo imposible la vuelta al modelo racionalista de planificación intercomunal.

47 Mattos, 2008, p. 7. 


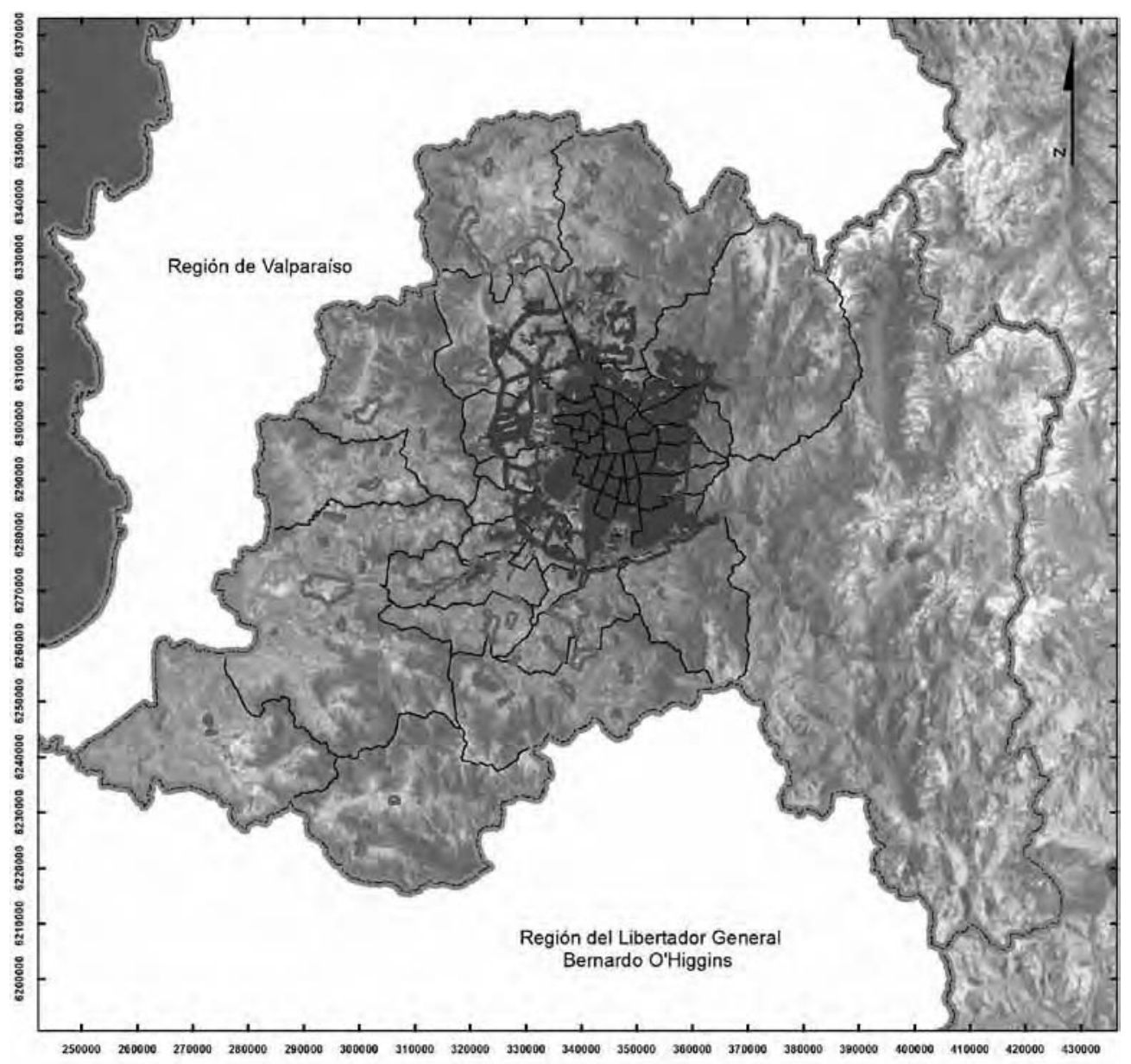

FIGURA 3.

EVOLUCIÓN

DEL LÍMITE

PLANIFICADO $Y$

MANCHA URBANA

DE SANTIAGO,

2012.

Fuente: Xlab, Instituto de Estudios Urbanos y $\mathrm{Te}$ rritoriales UC.

\section{Leyenda}

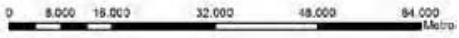

— Limite Urbano Propuesto PRMS 100

Limite Urbano Actual PRMS

Mancha Urbana

198 revista invi № 78 / Agosto 2013 / Volumen № 28: 181-219

ARTíCULO: El marco regulatorio en el contexto de la gestión empresarialista y la mercantilización del desarrollo urbano del Gran Santiago, Chile /

Magdalena Vicuña del Río 
En algunas comunas del territorio periurbano de Santiago, antes de la aprobación del PRMS se produjo un fuerte aumento en la subdivisión de predios rurales en parcelas de agrado de $5.000 \mathrm{~m}^{2}$. Según Naranjo, en la provincia de Chacabuco, en el sector norte de la región, se subdividió el 60,13\% de la superficie, esto es, 122.542 hectáreas. ${ }^{48}$ En el caso de la comuna de Til Til, hasta el año 1994 no se había aplicado el Decreto No 3.516. Sin embargo, entre los años 1994 y 1997 se subdividieron 26.639 hectáreas (41\% de la superficie comunal), producto de la aplicación del Decreto $\mathrm{N}^{\circ} 3.516$. En 1998, con la incorporación de la provincia de Chacabuco al PRMS, ya no fue posible la aplicación del mencionado decreto. Sólo se había consolidado un bajo porcentaje de estos predios, lo que confirma los procesos de especulación sobre el mercado de suelos. ${ }^{49}$

En el año 1997 por primera vez se modificó el PRMS, con la incorporación de la provincia de Chacabuco al área regulada por el plan y con la implementación de una nueva forma de regulación urbana, mediante las "zonas urbanas de desarrollo condicionado" (ZODUC) y las "áreas urbanizables de desarrollo prioritario" (AUDP), con lo que se incrementó en casi 15.000 hectáreas el suelo urbanizable en el Área Metropolitana de Santiago. ${ }^{50}$

48 Naranjo, 2009b, p. 12.

49 Naranjo, 2005.

50 Poduje, 2006, p. 258.
En el año 2003 se incorporó un nuevo instrumento normativo, los "proyectos de desarrollo urbano condicionado" (PDUC), que, a diferencia de las ZODUC y las AUDP, no contaban con una definición territorial explícita, pudiendo localizarse en cualquier sector de las zonas de interés silvoagropecuario de la región, siempre y cuando se cumpliera con las condicionantes establecidas (entre ellas, superficie de al menos 300 hectáreas, compromisos por etapas establecidas en un plan maestro, $12 \%$ de viviendas sociales y $18 \%$ de viviendas adquiridas con subsidio, compensaciones de suelos agrícolas, creación de una zona de transición de 250 metros y realización de un estudio de impacto urbano). Hasta ahora se han intentado implementar tres PDUC, con muchas dificultades en su aprobación.

En el año 2006 se amplió el ámbito de acción del PRMS a la totalidad del territorio de la Región Metropolitana, al incorporar las provincias de Melipilla y Talagante y las comunas de Buin y Paine (lo que aportó 9.000 nuevas hectáreas para el desarrollo del Gran Santiago). ${ }^{51}$

Por otro lado, si bien el PRMS establece normas de densidad para toda la Región Metropolitana, el mismo instrumento permite el aumento de densidad en las zonas rurales. A partir de la aplicación

51 Secretaría Regional Ministerial, Región Metropolitana (SEREMI Metropolitana), Ministerio de Vivienda y Urbanismo , 2006. 


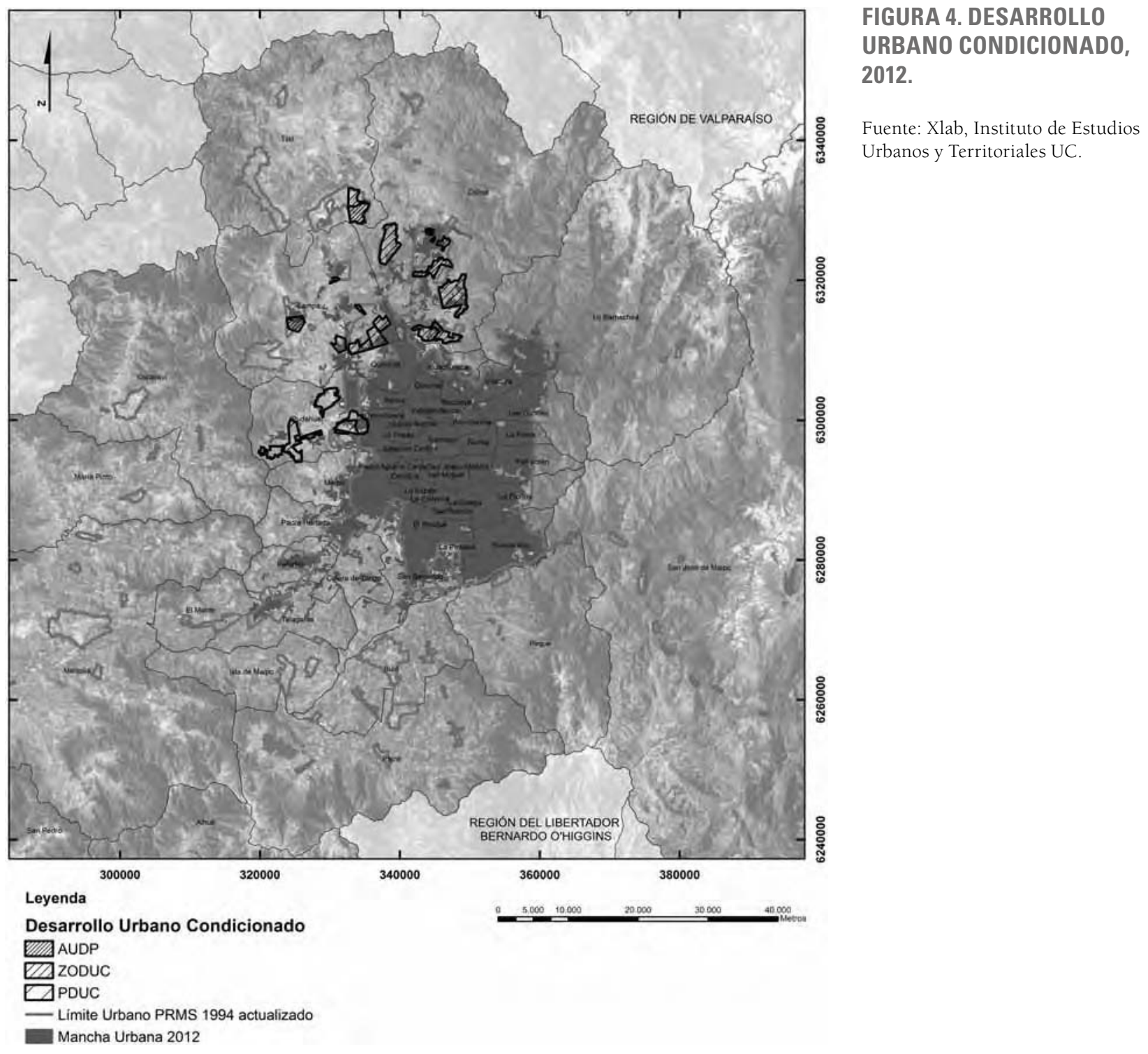


del Artículo 8.3.2, es posible emplazar conjuntos de viviendas sociales en terrenos de hasta $100 \mathrm{~m}^{2}$ de superficie, siempre que así lo solicite el municipio respectivo.

Fue así como se comenzó a consolidar un modelo de desarrollo urbano por condiciones, el cual, en teoría, busca canalizar las energías del mercado mediante el control y mitigación de los impactos de los proyectos, asignando los costos de urbanización a los desarrolladores inmobiliarios. El sector público ha impulsado este modelo, señalando que las condiciones impuestas a estos proyectos tienen como principales objetivos la integración socioeconómica a partir de la exigencia de porcentajes de vivienda social y con subsidio; y la integración funcional de los proyectos mediante la exigencia de porcentajes de equipamiento de servicios, infraestructura y áreas verdes.

Por su parte, el sector privado fundamenta el desarrollo condicionado por cuanto se sustenta en una mayor confianza en las fuerzas del mercado, argumentando que (1) el planificador no necesariamente se adelanta a la dinámica de crecimiento de las ciudades, lo que puede conducir a errores en la provisión de bienes públicos o a disyuntivas entre la regulación y las preferencias de los hogares; (2) la zonificación actúa mediante prohibiciones, no permitiendo que los involucrados solucionen sus diferencias a través de los mercados; y (3) la normativa es discrecional, el regulador queda expuesto a presiones interesadas y la zonificación no garantiza que las decisiones de localización incorporen los costos y beneficios que generan a la sociedad. ${ }^{52}$

Actualmente está en trámite de aprobación la última modificación al PRMS, la llamada modificación "PRMS 100", la cual amplía el límite urbano en 10.262 hectáreas de zonas urbanizables condicionadas. Estas zonas tienen una densidad base de 16 hab/ha, la que puede aumentarse hasta 165 hab/ha si es que se cumple con las siguientes condiciones: (1) que el terreno tenga una superficie de al menos 60 hectáreas; (2) que por un mínimo de cinco años se materialicen y mantengan áreas verdes de una superficie de, al menos, la proporción correspondiente a la superficie del predio que solicita la factibilidad; (3) que se destine un $6 \%$ a equipamientos; (4) que se materialice la vialidad del sector y sus conexiones con la vialidad existente; y (5) que se cuente con al menos un $8 \%$ del terreno destinado a uso residencial para vivienda social. ${ }^{53}$

Es necesario destacar que los proyectos inmobiliarios desarrollados a partir de las nuevas formas de planificación condicionada no habrían sido

\footnotetext{
52 Hurtado, 2007.

53 Secretaría Regional Ministerial(SEREMI), Región Metropolitana, Ministerio de Vivienda y Urbanismo Metropolitana, 2011a.
} 
posibles sin la implementación del Plan de Concesiones de Autopistas Urbanas del MOP. Si bien en la década de 1980 la inversión en infraestructura urbana por parte del Estado se redujo al mínimo, durante la década de 1990 se desarrolló un fuerte impulso por medio de una política de aportes en infraestructura, en la cual, además de la inversión pública, se incorporó la inversión del sector privado a través del mecanismo de las concesiones.

Así, el mecanismo de las zonas de desarrollo urbano condicionado, en todas sus versiones, ha permitido "que las estrategias, decisiones y acciones que expresan las preferencias locacionales de las empresas y de las familias, en especial de las de mayores recursos, puedan materializarse con mucha más autonomía y libertad efectiva que [en un contexto normativo] más regulado, lo que resulta de fundamental importancia para explicar los cambios que [han afectado] a las ciudades" ${ }^{54}$

A partir de la trayectoria presentada por los instrumentos de planificación intercomunal en el Gran Santiago, es evidente cómo se ha ido sustituyendo lo que Theodore, Peck y Brenner han denominado lógicas regulatorias redistributivas, por lógicas competitivas, ${ }^{55}$ transfiriéndose los riesgos y las responsabilidades asociados al desarrollo urbano a los municipios, los cuales muchas veces se ven sobrepasados en términos administrativos y de

54 Mattos, 2008, p. 10.

55 Theodore, Pecky Brenner, 2009, p. 2.

202 revista invi № 78 / Agosto 2013 / Volumen № 28: 181-219 gestión. En otras palabras, la zonificación como mecanismo de planificación y control del crecimiento urbano estaría en retroceso, dand paso a nuevas formas de gestión urbana.

En tanto, es posible observar el surgimiento del concepto de "horizontalidad" en las condiciones de regulación de la ciudad, mencionado en el primer punto de este trabajo. Tal como señala Sierra, las ZODUC corresponderían a un nuevo paradigma en la planificación urbana nacional, en cuanto corresponden a un modelo "horizontal" de relación entre los organismos públicos y el sector privado, como podrían ser los contratos de asociación y los mecanismos de compensación y distribución equitativa de derechos de construcción. ${ }^{56}$

La "horizontalidad" de la planificación por condiciones estaría dada por el mecanismo de negociación de las condiciones que el privado debe cumplir para poder realizar su desarrollo inmobiliario, en relación con las mitigaciones de impactos y externalidades que pueda generar.

En el nuevo enfoque "empresarialista" del Estado y en relación con lo se ha denominado participación consensuada, es central la figura de asociación público-privada. A partir de dicha figura — que en Chile ha tenido su mayor exponente en la concesión de autopistas urbanas y carreteras - se ha

$56 \quad$ Sierra, 2006, p. 325.

ARTíCULO: El marco regulatorio en el contexto de la gestión empresarialista y la mercantilización del desarrollo urbano del Gran Santiago, Chile / 
intentado resolver la dificultad por parte del Estado de implementar y mantener ciertas infraestructuras y servicios.

En el contexto urbano del Estado empresarialista, no sólo las autopistas urbanas del Gran Santiago han sido concesionadas, sino que también comienza a cobrar protagonismo la privatización de espacios públicos, como un mecanismo para la implementación y mantención de plazas, parques, galerías y paseos. Así, en el Gran Santiago coexisten figuras normativas y de gestión, tales como: (1) la Ley de Concesiones del Subsuelo, la cual entrega a las municipalidades la atribución de administrar el subsuelo de los bienes nacionales de uso público y las faculta para entregarlo en concesión para su utilización, previa licitación pública (este mecanismo se ha usado principalmente para la habilitación de estacionamientos y locales comerciales); (2) la Ley de Financiamiento Urbano Compartido (2003); (3) las normas en los planes reguladores comunales que determinan incentivos de mayor constructibilidad para la generación de espacios públicos de propiedad privada; y, más recientemente, 4) la concesión de plazas y parques urbanos.

Algunos de estos mecanismos han sido más exitosos que otros, como los incentivos de mayor constructibilidad o la concesión del subsuelo. Es lo ocurrido en comunas como Santiago, Providencia o Las Condes, las cuales dan la posibilidad de que el privado ceda a uso público parte del terreno o mejore las condiciones del espacio público existente, a cambio de un premio de mayor constructibilidad que la establecida en el Plan Regulador Comunal. Otros mecanismos son más cuestionables, como la concesión de bienes nacionales de uso público, ya que atenta contra el libre uso de dichos espacios por parte de todos los ciudadanos.

Otro ejemplo del modelo horizontal en la gestión de la ciudad corresponde a los diversos convenios que los operadores de grandes proyectos urbanos realizan con el gobierno local o central, según corresponda. El marco de este proceso de negociación es la Ley $N^{\circ} 19.300$ de Bases de Medioambiente, la cual define que los estudios de impacto ambiental de dichos proyectos deben dejar establecidas las obras de mitigación, compensación o reparación apropiadas. Una muestra de ello son las inversiones en infraestructura vial realizadas y por realizar por proyectos como Ciudad Empresarial (parque de negocios que se localiza en el sector norte de la ciudad, inmediato a la Autopista Américo Vespucio Express, que cuenta con más de 600 empresas); Nueva Las Condes (centro de servicios de alrededor de 13 hectáreas de superficie, con oficinas de alto estándar y localizado en el cono de alta renta de la ciudad, frente al Parque Araucano) y el recientemente inaugurado Costanera Center (complejo de servicios y comercio de más de $700.000 \mathrm{~m}^{2}$ de superficie, localizado en un terreno de 4,7 hectáreas en la comuna de Providencia, en el principal distrito de servicios de la ciudad). 
En el caso del proyecto Costanera Center, el año 2009 se definieron las medidas de mitigación que debía implementar el desarrollador en el espacio público y la infraestructura vial del sector aledaño al proyecto. Este proyecto está compuesto de cuatro torres de oficinas, hoteles y un mall, cinco niveles de subterráneos y un total de 5.695 estacionamientos.

Como lo establece la Ley $\mathrm{N}^{\circ}$ 19.300, las obras de mitigación se plantearon por etapas, las que se determinaron según la cantidad de estacionamientos que se irían implementando a lo largo del desarrollo del proyecto. Entre estas medidas se cuentan el ensanche de avenidas, la habilitación de un puente por el río Mapocho para conectar con el sistema vial de la autopista Costanera Norte, mejoras en diversos cruces, consolidación de ciclovías, implementación de pasarelas peatonales, ampliación de aceras e instalación de escaleras mecánicas hacia el espacio público, así como una serie de mecanismos de gestión de vías relacionados con la semaforización, la gestión peatonal y los estacionamientos en el sector. ${ }^{57}$

\section{El neoliberalismo y la planificación comunal del Gran Santiago: ajustes técnico-urbanísticos al proyecto neoliberal en la escala local de administración}

Se ha señalado que es inherente al neoliberalismo realmente existente una condición multiescalar. En consecuencia, no sólo la planificación a escala intercomunal y regional ha respondido a las nuevas condiciones económicas del neoliberalismo, sino que también lo ha hecho la planificación comunal. En efecto, en el nivel local de administración urbana del Gran Santiago es posible observar los ajustes técnico-urbanísticos a los instrumentos de planificación territorial ${ }^{58}$ en estrecha relación a los objetivos de la actividad inmobiliaria, como un medio para limitar el desarrollo inmobiliario o, por el contrario, para incentivarlo.

58 López-Morales, Gasic y Meza, 2012. 
Con posterioridad a la creación del PRMS en 1994 y en el contexto de la Reforma Urbana, el Ministerio de Vivienda y Urbanismo (MINVU) dio inicio al Plan de Actualización de Planes Reguladores Comunales (PRC), con la finalidad de responder al "modelo de la economía social de mercado, el cual plantea el desafío de planificar oportunamente y con agilidad, entendiendo el desarrollo en su doble dimensión: socioeconómica y territorial, en permanente interacción". ${ }^{59}$ Con una inversión de 15 millones de dólares, el Plan de Actualización de PRC se aplicó a más de doscientas comunas del país, las cuales debían cumplir con alguno de los siguientes requisitos: ausencia de instrumento de planificación territorial, población mayor a 30.000 habitantes urbanos, planes reguladores comunales de data mayor a veinte años o constituir nuevas comunas. ${ }^{60}$

Algunas comunas del Gran Santiago, tales como Santiago (correspondiente al centro histórico), Providencia o Las Condes (estas dos últimas pertenecientes al cono de alta renta), ya habían dado inicio por cuenta propia a la modificación de sus planes reguladores comunales, con el objetivo de regular la expansión de la actividad inmobiliaria desarrollada durante las décadas de 1980 y 1990.

59 Ministerio de Vivienda y Urbanismo (MINVU), División de Desarrollo Urbano, 1999, p. 3.

60 Ministerio de Vivienda y Urbanismo (MINVU), División de Planificación Urbano, 2007.
La maximización de la rentabilidad del suelo, amparada por planes reguladores extremadamente permisivos, ha sido uno de los factores que más impacto han tenido en la reciente transformación de algunas áreas de la ciudad. Comunas como Santiago, Providencia y Las Condes debieron imponer restricciones de altura y densidad para preservar la calidad de la edificación y el espacio público, así como niveles aceptables de congestión. Dichas comunas han intentado regular la actividad inmobiliaria, con el objetivo de compatibilizar inversión con calidad del espacio urbano.

El caso reciente de modificación a la normativa del centro histórico de la comuna de Santiago ejemplifica cierto aspecto de los ajustes técnico-urbanísticos asociados al urbanismo neo-liberal. En el año 1989 se había aprobado una regulación extremadamente flexible, la cual permitió que el número de permisos de edificación se incrementara en la comuna de alrededor de 40.000 en 1990 a más de 737.000 en 2005. ${ }^{61}$ En tanto, en el año 2003 se aprobó la primera modificación al sector Santiago Poniente, con la finalidad de preservar el patrimonio arquitectónico del casco antiguo de la ciudad, el cual se encontraba en inminente riesgo frente a la actividad inmobiliaria asociada a la renovación urbana. ${ }^{62}$ En 2008 se visó la modificación del

61 Froimovich et al., 2006.

62 Al respecto, ver López-Morales, Gasic y Meza, 2012. 
centro histórico (correspondiente al triángulo fundacional de la ciudad). Esta modificación estableció un tipo de control de la densidad para los edificios en altura sin precedentes en la planificación comunal de Chile: la densidad no se regula a partir de las viviendas o habitantes por hectárea, sino que se establece para cada proyecto de viviendas en altura, un máximo del 40\% de departamentos con superficies útiles inferiores o iguales a $40 \mathrm{~m}^{2}$ y un $40 \%$ de departamentos con superficies útiles superiores o iguales a $50 \mathrm{~m}^{2}$. Además, si este último porcentaje es incrementado en un $25 \%$, se permite aumentar la constructibilidad hasta alcanzar en algunas zonas un coeficiente de 9.

El año 2011 se acordó la modificación de la ordenanza para los barrios República, Almagro y Santa Isabel. La edificación pre-existente en estos barrios es mayoritariamente de agrupamiento continuo, de 1 a 2 pisos de altura, con algunas edificaciones de hasta 4 pisos. Desde la década del 2000 la inversión inmobiliaria aumentó de forma significativa, impulsando un importante proceso de renovación y transformación urbana, que ha tenido consecuencias morfológicas como la fragmentación de la manzana y el espacio público, así como también lo que se ha denominado "verticalización" del espacio urbano. ${ }^{63} \mathrm{El}$ proceso de densificación ha sido significativo y de gran intensidad, alcanzando en algunos lotes densidades netas de hasta 10.000 habitantes por hectárea (Figuras 5 y 6).

La nueva normativa para estos sectores de la comuna pone énfasis en la designación de una significativa cantidad de inmuebles y zonas protegidas como de conservación histórica, condicionantes morfológicas especiales para que las nuevas edificaciones dialoguen de forma más armónica con el contexto histórico existente; y plantea importantes restricciones a la densidad, con la finalidad de aumentar la superficie de las viviendas y mejorar el stock habitacional.

Otro ejemplo de ajuste normativo es la Modificación al Plan Regulador de Providencia (2007), comuna que llevaba ya casi tres décadas en proceso de densificación. Mediante ese instrumento, el municipio redujo los coeficientes de constructibilidad, ${ }^{64}$ de manera de adelantarse a los aumentos de superficie construida posibilitados por el Artículo 63 de la Ley LGUC, el cual permite el aumento de

63 Froimovich et al., 2006.

64 En efecto, el "coeficiente de constructibilidad" corresponde al número que multiplicado por la superficie total del predio, descontadas de esta última las áreas declaradas de utilidad pública, fija el máximo de metros cuadrados posibles de construir sobre el terreno (Ordenanza General de Urbanismo y Construcciones, 2012). mercantilización del desarrollo urbano del Gran Santiago, Chile / 
FIGURA 5. DENSIFICACIÓN EN ALTURA EN 5 MANZANAS DEL BARRIO ALMAGRO, EN LA COMUNA DE SANTIAGO.

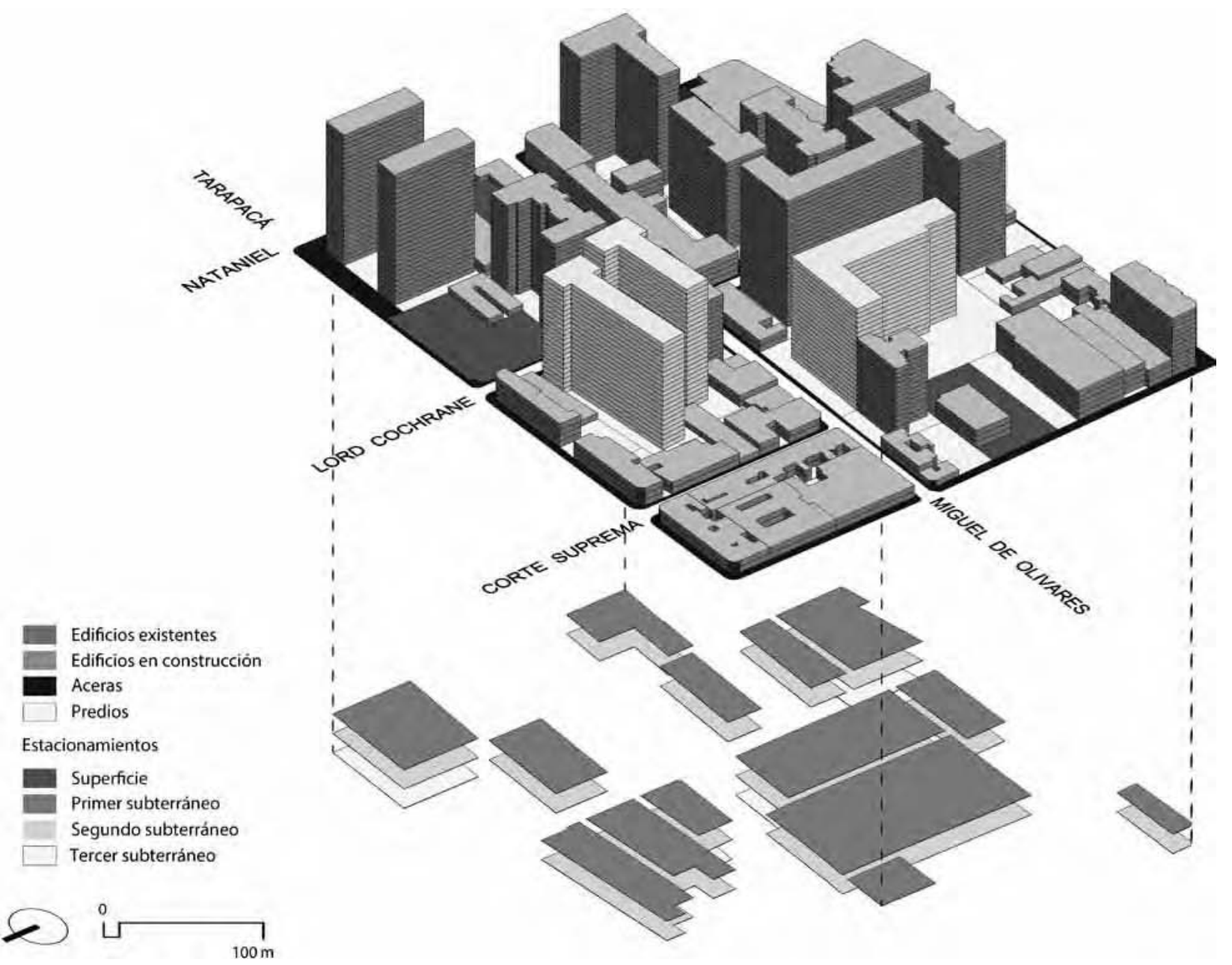

Fuente: Elaboración propia en base a permisos de edificación otorgados por la Dirección de Obras de la Municipalidad de Santiago. 


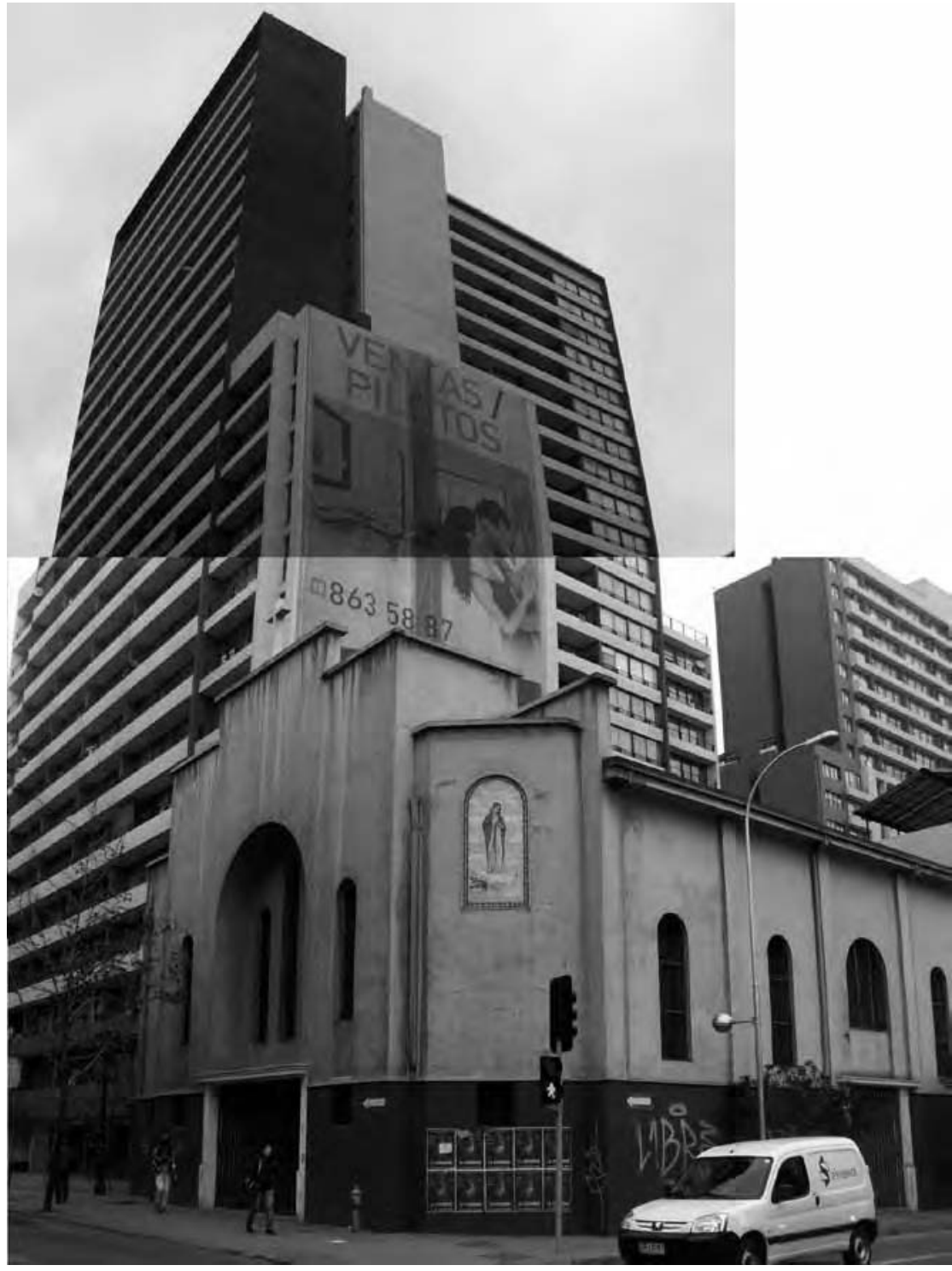

FIGURA 6. VISTA DE LA CALLE NATANIEL COX, BARRIO ALMAGRO, COMUNA DE SANTIAGO.

Fuente: Elaboración propia 
TABLA 2. COEFICIENTES DE CONSTRUCTIBILIDAD NORMADOS POR PROVIDENCIA Y LOS ALCANZADOS CON LOS BENEFICIOS DE FUSIÓN PREDIAL Y DFL2.

\begin{tabular}{llll}
$\begin{array}{l}\text { Zona del Plan } \\
\text { Regulador }\end{array}$ & $\begin{array}{l}\text { Coeficiente de } \\
\text { constructibilidad normado }\end{array}$ & $\begin{array}{l}\text { Coeficiente de constructibilidad } \\
\text { con fusión predial }\end{array}$ & $\begin{array}{l}\text { Coeficiente de constructibilidad } \\
\text { máximo DFL N } 2\end{array}$ \\
\hline EC3 & 1,1 & 1,43 & 1,72 \\
\hline EC5 & 1,8 & 2,34 & 2,81 \\
\hline EC7 & 2,5 & 3,25 & 3,9 \\
\hline EC12 & 4,3 & 5,59 & 6,71 \\
\hline Edificación continua más aislada & & 1,87 \\
\hline EC2+A5 & $1,2 / 1,2$ & $1,56 / 1,56$ & 2,5 \\
\hline EC2+A8 & $1,2 / 1,6$ & $1,6 / 2,08$ & 6,24 \\
\hline EC3+AL & $3 / 4$ & $3,9 / 5,2$ & 1,87 \\
\hline Edificación aislada permite adosamiento & & 2,5 \\
\hline EA5/pa & $1,2 / 0,6$ & 1,56 & 2,65 \\
\hline EA7/pa & $1,6 / 0,6$ & 2,08 & 4,52 \\
\hline EA12/pa & $1,7 / 0,6$ & 2,21 & 1,09 \\
\hline EAL/pa & $2,9 / 0,6$ & 3,77 & 1,87 \\
\hline Edificación aislada & & & 2,5 \\
\hline EA3 & 0,7 & 0,91 & 2,65 \\
\hline EA5 & 1,2 & 2,56 &
\end{tabular}

Fuente: Elaboración propia a partir de Memoria Explicativa, Plan Regulador Comunal de Providencia, 2007. 
un $30 \%$ de constructibilidad a los proyectos que realizan fusión predial, ${ }^{65}$ o por el Artículo 6.1.5 de la OGUC, el cual no considera las superficies comunes de los edificios de vivienda colectiva en el cálculo de la constructibilidad de la vivienda económica. ${ }^{66}$

De esta manera, si el coeficiente normado por la municipalidad en el Plan Regulador es de 1.1 (Zona EC3), por ejemplo, se espera que el coeficiente que realmente se construya sea de 1.72 y así sucesivamente en las otras zonas del Plan Regulador (Tabla 2). A su vez, la comuna de Providencia estableció límites de densidad a los proyectos no sólo en habitantes por hectárea, sino también en viviendas por hectárea, para asegurar un tamaño mínimo de los departamentos.

Por el contrario, como han documentado LópezMorales, Gasic y Meza, otras comunas se acogieron al Plan de Actualización de Planes Reguladores del MINVU (o ya habían empezado por cuenta propia), con la finalidad de atraer inversiones

65 El Artículo 63 de la LGUC establece: “La fusión de dos o más terrenos en uno solo tendrá un beneficio de mayor densidad, a través de aumentar el coeficiente de constructibilidad del predio en un $30 \%$. Cuando resulten terrenos de $2.500 \mathrm{~m}^{2}$ o más, podrán acogerse a los beneficios que otorga el concepto de 'Conjunto Armónico'".

66 Según la Ordenanza General de Urbanismo y Construcciones, la vivienda económica es aquella que no supera los $140 \mathrm{~m}^{2}$ construidos y que reúne los requisitos, características y condiciones de urbanización y arquitectura que se fijan en la Ordenanza General de Urbanismo y Construcciones. inmobiliarias. Tal es el caso de municipios como Recoleta, Independencia, San Miguel, Nuñoa, Macul, Quinta Normal y Estación Central, las cuales corresponden al anillo pericentral de Santiago; o comunas como Huechuraba, La Florida o Peñalolén, las cuales, si bien son más periféricas, ofrecen atributos de localización relativa por la presencia de autopistas urbanas y la red de metro (Figura 1). Dichas comunas, como han confirmado los autores mencionados, han establecido vínculos con el sector privado, de manera que las decisiones en relación a la planificación urbana son, a lo menos, convergentes con los objetivos del sector inmobiliario.

Otro aspecto de relevancia en la escala local es el límite urbano, instrumento normativo mencionado en el punto anterior, cuya injerencia es determinante del valor de suelo y su potencial plusvalía. En el caso de Santiago, tanto las zonas de desarrollo condicionado como la propuesta modificación del PRMS ("PRMS 100") han tenido y tendrán importantes impactos a escala comunal. Si bien para 
los municipios el cambio de uso de suelo es bienvenido, porque significa mayores recursos para la comuna, el brusco incremento de la población y la carga administrativa, en oportunidades se hace inmanejable.

\section{El hibridismo de la neoliberalización y sus múltiples contradicciones}

Theodore, Peck y Brenner plantean que el neoliberalismo realmente existente conlleva un necesario hibridismo, por cuanto en éste conviven diversas formas políticas y regulatorias. En oportunidades, el hibridismo implica la existencia de contradicciones entre los objetivos de dichas formas institucionales. En el caso del urbanismo neoliberal chileno, estas contradicciones se manifiestan, particularmente, entre las distintas escalas de planificación y entre los mecanismos del urbanismo reglamentario y operacional, como por ejemplo, entre la LGUC y OGUC y las competencias propias de la planificación urbana local.

A pesar de las restricciones impuestas por algunos planes reguladores comunales para controlar y dirigir la inversión inmobiliaria, aún coexisten formas de regulación urbana centralizadas a través de la LGUC, cuya aplicación está por encima de lo dispuesto en las normativas locales. Dichas regulaciones operan a partir de normas "de excepción", tales como el mencionado Artículo 63, que establece un premio por la fusión predial en las operaciones inmobiliarias; el Artículo 55, que permite construir vivienda social fuera del límite urbano establecido en los planes reguladores; o los artículos referidos a la norma de Conjunto Armónico, figura que permite aumentar la constructibilidad y la altura de un edificio, sin perjuicio de las normas establecidas en el Plan Regulador Comunal correspondiente.

El Artículo 55 determina la prohibición de la localización de viviendas fuera del límite urbano, con excepción de las viviendas sociales o viviendas de hasta un valor de 1.000 unidades de fomento y que cuenten con los requisitos para obtener el subsidio del Estado. En la OGUC se establecen las condiciones mínimas de urbanización para dichos conjuntos de vivienda localizados en zonas rurales. No obstante, dicha norma es contradictoria, puesto que también señala que corresponde a la autoridad regional de vivienda cautelar que las subdivisiones y construcciones en suelos rurales no originen nuevos núcleos urbanos al margen de la planificación urbana-regional.

Por su parte, la aplicación del Artículo 6.1.8 de la Ordenanza General de Urbanismo y Construcciones permite prescindir de algunas normas establecidas por los municipios a través de los planes reguladores comunales, como los requerimientos de 


\section{FIGURA 7. URBANISMO EX - POST. VIVIENDA SOCIAL EN EL PERI - URBANO DE COLINA, SANTIAGO.}

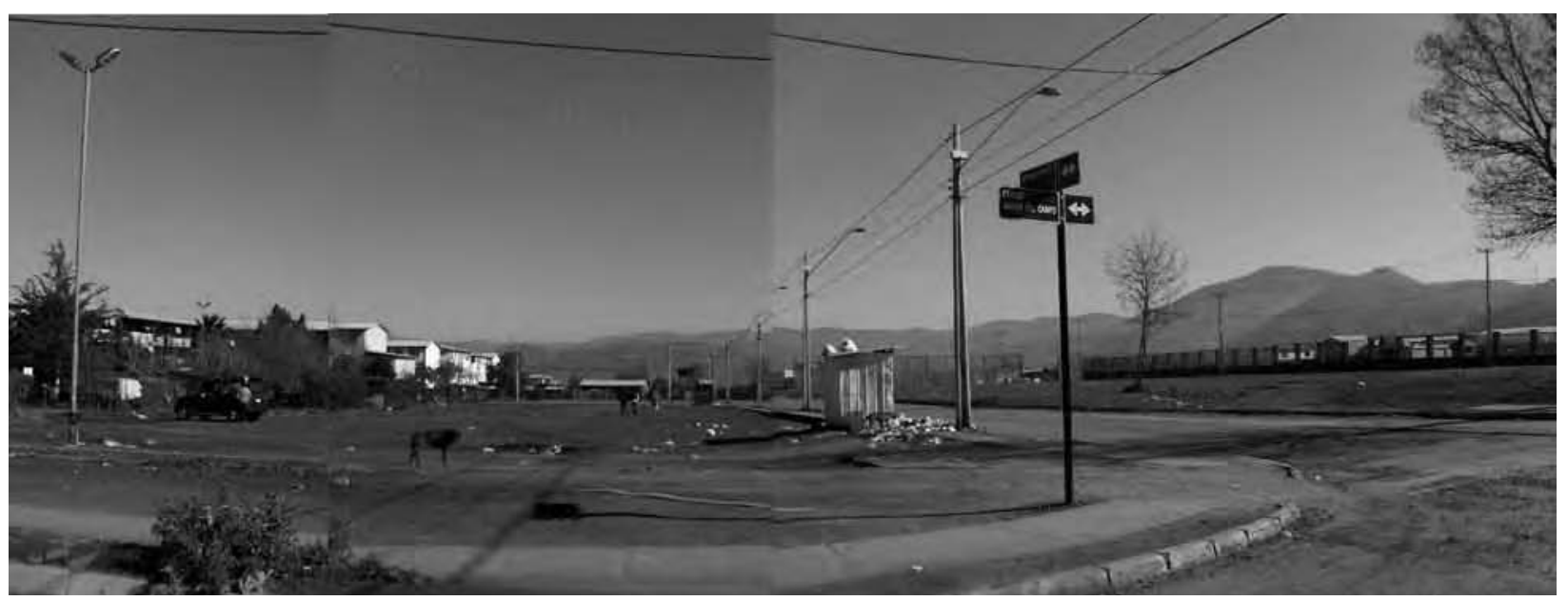

Fuente: Elaboración propia.

constructibilidad o de ocupación de suelo, siempre y cuando se trate de viviendas económicas y se cumpla con ciertos requisitos de altura máxima. Esta norma incluso permite que en dichos conjuntos de vivienda se aumente hasta en $25 \%$ la densidad máxima establecida por el plan regulador comunal.

Producto de la aplicación de estas normas de excepción para el desarrollo urbano en extensión, así como del Artículo 8.3.2 del PRMS, se ha expandido aceleradamente la mancha urbana a partir de grandes conjuntos monofuncionales de vivienda social en torno a las localidades rurales periféricas al Gran Santiago, tales como Colina, Talagante, Peñaflor, Buin, Isla de Maipo o Lampa, entre otras. Una vez construidas, estas nuevas áreas residenciales se incorporan al límite urbano del PRMS, fenómeno conocido como urbanismo ex - post. Así, la aplicación de dichos instrumentos normativos refuerza la discontinuidad entre la ciudad existente y los nuevos conjuntos de vivienda social. 
Si bien aún quedan rastros del urbanismo racionalista en los planteamientos originales del PRMS, coincidimos con De Mattos en que a partir del modelo económico liberal, la financiarización de las economías y el aumento explosivo de las inversiones inmobiliarias en la ciudad, se ha producido en el Gran Santiago, a nivel de planificación intercomunal, un abandono prácticamente total y definitivo de la confianza en los mecanismos tradicionales de zonificación de usos de suelo, situación que se replica en otras ciudades del país.

\section{Comentarios conclusivos}

Como hemos podido observar a partir del caso del "neoliberalismo realmente existente" en el desarrollo del Gran Santiago, la regulación urbana tiene un rol fundamental. En el contexto de la gestión urbana subsidiaria y empresarialista y de la mercantilización del desarrollo urbano producto del neoliberalismo, durante las últimas décadas la regulación urbana se ha ido ajustando en concordancia con el contexto político y económico del país, ya que respondió a un modelo centralizado durante la década de 1960, se sumó al proyecto neoliberal en la década de 1980 e intentó volver al paradigma de la zonificación y el límite urbano con el retorno de la democracia en la década de
1990. Sin embargo, a pesar de los objetivos de planificadores y urbanistas, las fuerzas del mercado inmobiliario, apoyadas por la inversión en autopistas urbanas, han dado paso a un modelo híbrido, en el cual conviven una planificación vertical y jerarquizada, con nuevos modos de relación horizontal entre el sector público y privado.

Por otro lado, el neoliberalismo realmente existente se materializa a través de formas híbridas y en oportunidades contradictorias, las cuales hacen que cada ciudad se manifieste como una coyuntura urbana específica. Es justamente a partir de dichos contextos híbridos desde donde se configuran tanto la forma como las consecuencias de las estrategias reestructuradoras del urbanismo neoliberal. ${ }^{67}$ En el caso chileno, tanto la LGUC como la OGUC cuentan con una serie de "normas de excepción", mecanismos que permiten no adscribirse a las normas locales de planificación, cuando se trata de importantes proyectos de densificación o de conjuntos de vivienda económica y social.

En este contexto, se hace fundamental la coherencia entre mecanismos del "urbanismo reglamentario" y los del "urbanismo operacional", de manera que las comunas que integran el Gran Santiago puedan contar con competencias efectivas de gestión para el crecimiento y desarrollo de su territorio.

67 Theodore, Peck y Brenner, 2009. 
Theodore, Peck y Brenner señalan que el neoliberalismo destructivo de la década de 1980 ha quedado atrás, dando paso a nuevas "formas neoliberales de creación institucional [que] ya no se orientan simplemente hacia la promoción de un crecimiento capitalista impulsado por el mercado, sino también hacia el establecimiento de nuevos 'mecanismos complementarios' y otras formas de desplazamiento de las crisis, a fin de blindar a los actores e intereses económicos poderosos frente a las fallas endémicas de los mercados y regímenes de gobernanza". ${ }^{68}$ Si bien la planificación por condiciones o la asociatividad público-privada son ejemplos de dichos mecanismos complementarios, éstas se constatan sólo en los instrumentos de planificación de aquellas comunas del Gran Santiago que cuentan con mecanismos para realizar ajustes técnico-urbanísticos y normativos, los cuales se implementan principalmente en el cono de alta renta de la ciudad. Por otro lado, aquellas comunas con menores recursos económicos y profesionales para planificar su territorio, o aquellas que buscan atraer inversiones inmobiliarias con la finalidad de generar desarrollo económico local, carecen de las capacidades necesarias para resistir al modelo, o simplemente no presentan la voluntad de hacerlo.

En la regulación urbana actual del Gran Santiago podemos constatar lo que Theodore, Peck y Brenner definen como una relación "parasitaria" del

68

214 revista invi № 78 / Agosto 2013 / Volumen № 28: 181-219

8 Theodore, Peck y Brenner, 2009, p. 10. neoliberalismo con otras formas de Estado. Así, en la regulación urbana actual del Gran Santiago encontramos, por un lado, mecanismos como el Artículo 55, el desarrollo condicionado o el conjunto armónico; y por otro, instrumentos de planificación convencional como el PRMS y los planes reguladores comunales, los cuales intentan imponer restricciones al crecimiento urbano, usos de suelo, límites de densidad y preservación de áreas naturales o de conservación histórica, aunque no siempre con éxito.

Hoy encontramos una contradictoria convivencia entre mecanismos regulatorios que imponen un límite urbano (como el PRMS) y otras operaciones que potencian el desarrollo de proyectos residenciales fuera del área urbana (como el Plan de Concesiones de Autopistas Urbanas, el cual multiplica las opciones de vivienda suburbana). Se trata de una contradicción cuyo origen se encuentra, en parte, en la falta de coordinación entre las políticas públicas impulsadas por el Ministerio de Vivienda y Urbanismo (PRMS), y las del Ministerio de Obras Públicas y Transportes (Plan de Concesiones). Estas discordancias podrían corresponder a lo que Theodore, Peck y Brenner definen como "múltiples contradicciones", que en el caso de Santiago han llevado a una seguidilla de ajustes al principal instrumento de planificación de la ciudad. 
Otra forma de analizar la condición de hibridismo anteriormente señalada, es a partir del modelo horizontal de regulación en la producción de ciudad. Como señalábamos, estos elementos de negociación son esencialmente flexibles. Sin embargo, para Sierra, este no es un avance demasiado grande en un escenario en que la potestad administrativa puede interrumpir avasalladoramente en cualquier momento, por medio de la LGUC, la OGUC e incluso el PRMS. ${ }^{69}$

Tanto el urbanismo operacional como el reglamentario deben encaminarse más allá de la planificación por condiciones, en la cual el desarrollador debe compensar y mitigar los impactos generados por el proyecto. Sin embargo, hasta el momento las zonas y los proyectos de desarrollo condicionado no han implementado la integración social y funcional esperada.

También se hace necesaria la implementación de mecanismos que permitan a los municipios un mayor control de los efectos que las inversiones privadas tienen en su territorio. En este sentido, el proyecto de modificación a la LGUC, el cual desde el año 2004 se tramita en el Congreso, establece herramientas que, eventualmente, permitirán a los municipios y a las comunidades un rol más activo en la materia. Algunos de los lineamientos más relevantes que establece la modificación son

69 Sierra, 2006. la participación ciudadana en la formulación de los planes reguladores; los mecanismos de diseño urbano y la actualización oportuna de los planes; la incorporación de condicionamientos al desarrollo urbano en los planes reguladores; los mecanismos de compensación y distribución equitativa de derechos de construcción y planes de recuperación de barrios y sectores, entre otros. ${ }^{70}$

A pesar de que aún quedan importantes resonancias de la verticalidad propia de la planificación centralista, podemos ver cómo estos lineamientos se orientan hacia un modelo horizontal, poniendo énfasis en mecanismos normativos distintos al de la zonificación, la cual cada vez tiene un rol menos relevante en la gestión de ciudades. Esto porque la gestión urbana actual crecientemente se basa en la creación de proyectos urbanos por sobre la planificación normativa a largo plazo.

Tal como ha señalado Harvey, el empresarialismo urbano requiere un nivel de competición interurbana. Por tanto, la tarea de la gobernanza urbana consiste en gran medida en traer a la ciudad una producción altamente flexible y movible, en términos financieros y flujos de consumo. ${ }^{71}$ En efecto, cabe preguntarse por la pertinencia de dichas modificaciones a la LGUC en el contexto del Gran Santiago y su rol en la competencia mundial de ciudades. Para participar en tal contienda no

70 Ministerio de Vivienda y Urbanismo, (MINVU), 2009.

71 Harvey, 1989, p. 11. 
sólo se requiere una plataforma regulatoria atractiva para la inversión privada del más alto nivel; también son requisitos la conservación histórica, la participación de la comunidad en la toma de decisiones respecto de las transformaciones del territorio, el acceso de los sectores más vulnerables a vivienda, espacios públicos y servicios de calidad y la integración espacial, entre muchos otros aspectos que hoy se presentan como desafíos.

\section{Bibliografía}

AGUIRRE, Beatriz y RABI, Salim. Trayectoria institucional de la CORVI. El paradigma de la CORVI en la arquitectura habitacional chilena, 1953-1976. [En línea]. Fondo de Información y Documentación (FID). 1998. Centro de Estudios de la Vivienda (CEDVI), Facultad de Arquitectura y Bellas Artes de la Universidad Central, Santiago de Chile. 55 p. [Fecha de consulta: 19 junio 2012]. Disponible en: http://www.ucentral. cl/fid/pdf/el_paradigma_dt9.pdf.

BARNETT, Jonathan. An introduction to urban design. New York, Harper \& Row. 1982. 260 p. ISBN 0-06-430376-4.

BRENNER, Neil y THEODORE, Nik. Cities and the geographies of "actually existing neoliberalism". [En línea]. Antipode. 34(3): 349-379, 2002. ISSN 1467-8330. Disponible en: http://dx.doi. org/10.1111/1467-8330.00246.
CARVACHO, Alberto. Plan regulador metropolitano de Santiago. SEREMI 1994. Revista CA. (81): 61-68, 1996. ISSN 0716-3622.

FROIMOVICH, Jocelyn; GARCÍA, Marisol; LEPORI, Gilberto y VERGARA, Javier. Transformación de la comuna de Santiago a partir de la vivienda: Revisión de un proceso de renovación urbana. Santiago, Chile, Pontificia Universidad Católica de Chile, Escuela de Arquitectura. 2006. 413 p. Memoria (Título de Arquitecto).

GALETOVIC, Alexander, ed. Santiago, dónde estamos y hacia dónde vamos. Santiago, Centro de Estudios Públicos CEP. 2006. 579 p. ISBN: 956-7015-39-2.

HARVEY, David. From managerialism to entrepreneurialism: The transformation in urban governance in late capitalism. [En línea]. Geografiska Annaler, Series B, Human Geography. 71(1): 3-17, 1989. ISSN 1468-0467. Disponible en: http://www. jstor.org/stable/490503.

HURTAD0, Javier. Desarrollos urbanos condicionados, ¿por qué? y ipara qué? En: Seminario Desarrollos Condicionados. Santiago de Chile, Cámara Chilena de la Construcción. 2007.

LÓPEZ-MORALES, Ernesto José; GASIC, Ivo Ricardo y MEZA, Daniel Alberto. Urbanismo pro-empresarial en Chile: políticas y planificación de la producción residencial en altura en el pericentro del Gran Santiago. [En línea]. Revista INVI. 27(76): 75-114, noviembre 2012. ISSN 0718-8358. 
Disponible en: http://dx.doi.org/10.4067/ S0718-83582012000300003.

MASSONE, Claudio. Decreto 420, planificación urbana 1979-1990. Revista CA. (81): 56-61, 1996. ISSN 0716-3622.

MATTOS, Carlos A.. de. Globalización, negocios inmobiliarios y mercantilización del desarrollo urbano. En: PEREIRA, Paulo César Xavier, ed. e HIDALGO, Rodrigo, ed. Producción inmobiliaria y reestructuración metropolitana en América Latina. Santiago, Instituto de Geografía, Pontificia Universidad Católica de Chile, Facultad de Arquitectura y Urbanismo de la Universidad de Sao Paulo. 2008. p. 23-40. ISBN 9789561410022. Serie GeoLibros $N^{\circ} 11$

MENSAJE N 866-355. Mensaje de S.E., la Presidenta de la República Michelle Bachelet, con el que inicia un proyecto de ley que modifica la Ley General de Urbanismo y Construcciones en materia de planificación urbana. Santiago, Chile. 09 de diciembre de 2007. 41 p.

MINISTERIO de Agricultura. Decreto Ley No 3.516. Establece normas sobre división de predios rústicos. Diario Oficial de la República de Chile. Santiago, Chile, 01 de diciembre de 1980.

---- Oficio ordinario Nº939. Informe sobre Modificación del Plan Intercomunal de Santiago. Santiago, Chile. 1979. 5 p.

MINISTERIO de Obras Públicas (MOP). Publicación del decreto del Plan Regulador Intercomunal deSantiago y su ordenanza.
Diario Oficial de la República de Chile. Santiago, Chile, 27 de diciembre de 1960. 4 p.

MINISTERIO de Vivienda y Urbanismo (MINVU). DFL $\mathrm{N}^{\circ} 458$, Ley General de Urbanismo y Construcciones. Diario Oficial de la República de Chile. Santiago, Chile, 13 de abril de 1976. Versión de marzo de 2012. $81 \mathrm{p}$.

-.-- DS No 47, Ordenanza General de Urbanismo y Construcciones. Santiago, Chile. 16 de septiembre de 1992. Versión de abril de 2011. 375 p.

---- Precisiones a algunos conceptos contenidos en la Política Nacional de Desarrollo Urbano. Diario Oficial de la República de Chile. Santiago, Chile, 17 de diciembre de 1987. p. 4.

MINISTERIO de Vivienda y Urbanismo (MINVU). División de Desarrollo Urbano. Circular DDU No55. Santiago, Chile. 1999.

-.-- Política Nacional de Desarrollo Urbano. Santiago, Chile, MINVU. 1985. Colección Monografías y Ensayos, Serie VII, N²07.

MINISTERIO de Vivienda y Urbanismo (MINVU). División de Desarrollo Urbano, Departamento de Planificación Urbana. Resumen ejecutivo del programa de actualización de instrumentos de planificación territorial 2002-2007. Santiago, Chile. 2007. 24 p.

MINISTERIO de Vivienda y Urbanismo (MINVU). Dirección Jurídica. Decreto No 420, modificación del Plan Regulador Intercomunal de Santiago. Santiago, Chile, MINVU. 1979. 
MUNICIPALIDAD de Providencia, Secretaría Comunal de Planificación (SECPLA). Departamento de Asesoría Urbana. Modificación del Plan Regulador Comunal de Providencia, Memoria Explicativa. Santiago, Chile. 2007. 96 p.

MUNICIPALIDAD de Santiago. Asesoría Urbana. Modificación del Plan Regulador de Santiago, Sector Centro Histórico, Memoria Explicativa. Santiago, Chile. 2007. 47 p.

NARANJO RAMÍREZ, Gloria. Efectos de un instrumento de planificación en el periurbano de Santiago. Caso de Estudio: Comuna de Til Til. [En línea]. Scripta Nova Revista Electrónica de Geografía y Ciencias Sociales. 9(194)(38), 2005. ISSN 11389788. Disponible en: http://www.ub.edu/geocrit/ sn/sn-194-38.htm.

NARANJO RAMÍREZ, Gloria. El papel de la ciudad infiltrada en la expansión metropolitana de Santiago de Chile. [En línea]. Coloquio INJAVIU 2009: "Renovación, rehabilitación o expansión urbana: Elementos para el debate en el contexto iberoamericano". 2009b. [Fecha de consulta: 10 octubre 2012]. Disponible en: http://www.javeriana.edu.co/arquidis/injaviu/ coloquio/documents/2.1LaciudadInfiltrada.pdf.

NARANJO RAMÍREZ, Gloria. El rol de la ciudad infiltrada en la reconfiguración de la periferia metropolitana de Santiago de Chile. [En línea]. Estudios Geográficos. 70(266): 205-229, enero 2009a. ISSN 0014-1496. Disponible en: http://dx.doi. org/10.3989/estgeogr.0448.

PETERMANN, Alexandra. ¿Quién extendió Santiago? Una breve historia del límite urbano, 1953-1994.
En: GALETOVIC, Alejandro, ed. Santiago. Dónde estamos y hacia dónde vamos. Santiago, Chile, Centro de Estudios Públicos (CEP). 2006. p. 205230. ISBN: 956-7015-39-2.

PODUJE, Iván. El globo y el acordeón: Planificación urbana en Santiago, 1960-2004. En: GALETOVIC, Alejandro, ed. Santiago. Dónde estamos y hacia dónde vamos. Santiago, Chile, Centro de Estudios Públicos (CEP). 2006. p. 131-176. ISBN: 956-7015-39-2.

PONCE DE LEÓN, Macarena. Intercomunal de Santiago. Plan Regulador MOPT 1960. Revista CA. (81): 40-47, 1996. ISSN 0716-3622.

SCHLACK, Elke y VICUÑA, Magdalena. Componentes normativas de alta incidencia en la nueva morfología del Santiago Metropolitano. [En línea]. EURE. 37(111): 131-166, mayo 2011. ISSN 02507161. Disponible en: http://dx.doi.org/10.4067/ S0250-71612011000200006.

SECRETARÍA Regional Ministerial (SEREMI). Región Metropolitana, Ministerio de Transportes y Telecomunicaciones. Estudio de impacto sobre el sistema de transportes (EISTU), Proyecto Costanera Center. Oficio Ordinario No 036. Santiago, Chile. 2009.

SECRETARÍA Regional Ministerial (SEREMI). Región Metropolitana, Ministerio de Vivienda y Urbanismo. Memoria Explicativa. Modificación PRMS 100. Santiago, Chile. 2011a.

SECRETARÍA Regional Ministerial (SEREMI), Región Metropolitana, Ministerio de Vivienda y 
Urbanismo. Proposición Documento Memoria Explicativa Modificación Plan Regulador Metropolitano MPRMS 100 - Actualización de Áreas de Extensión Urbana y Reconversión. Santiago, Chile. 2011 b. 69 p.

SECRETARÍA Regional Ministerial (SEREMI). Región Metropolitana, Ministerio de Vivienda y Urbanismo. Plan Regulador Metropolitano de Santiago. Santiago de Chile. 2007.

SECRETARÍA Regional Ministerial (SEREMI). Región Metropolitana, Ministerio de Vivienda y Urbanismo. Modificación del Plan Regulador Metropolitano de Santiago $N^{\circ} 73$, que incorpora las comunas de Curacaví, María Pinto, Melipilla, San Pedro, Alhué, Padre Hurtado, Peñaflor, Talagante, Isla de Maipo, El Monte, Buin y Paine al área regulada por el Plan Regulador Metropolitano. Santiago, Chile. 2006.
SECRETARÍA Regional Ministerial (SEREMI). Región Metropolitana, Ministerio de Vivienda y Urbanismo. Modificación del Plan Regulador Metropolitano de Santiago que incorpora el artículo 8.3.2.4, correspondiente a los Proyectos con Desarrollo Urbano Condicionado. Santiago, Chile. 2003.

SIERRA, Lucas. Urbanismo por decreto: Centralismo y confusión institucional en la ciudad chilena. En: GALETOVIC, Alejandro, ed. Santiago. Dónde estamos y hacia dónde vamos. Santiago, Chile, Centro de Estudios Públicos (CEP). 2006. p. 299-328. ISBN: 956-7015-39-2.

THEODORE, Nik; PECK, Jamie y BRENNER, Neil. Urbanismo neoliberal: la ciudad y el imperio de los mercados. [En línea]. Temas Sociales. (66). 2009. [Fecha de consulta: 10 octubre 2012]. Disponible en: http://www.sitiosur.cl/publicacionescatalogodetalle. php?PID=3532. 


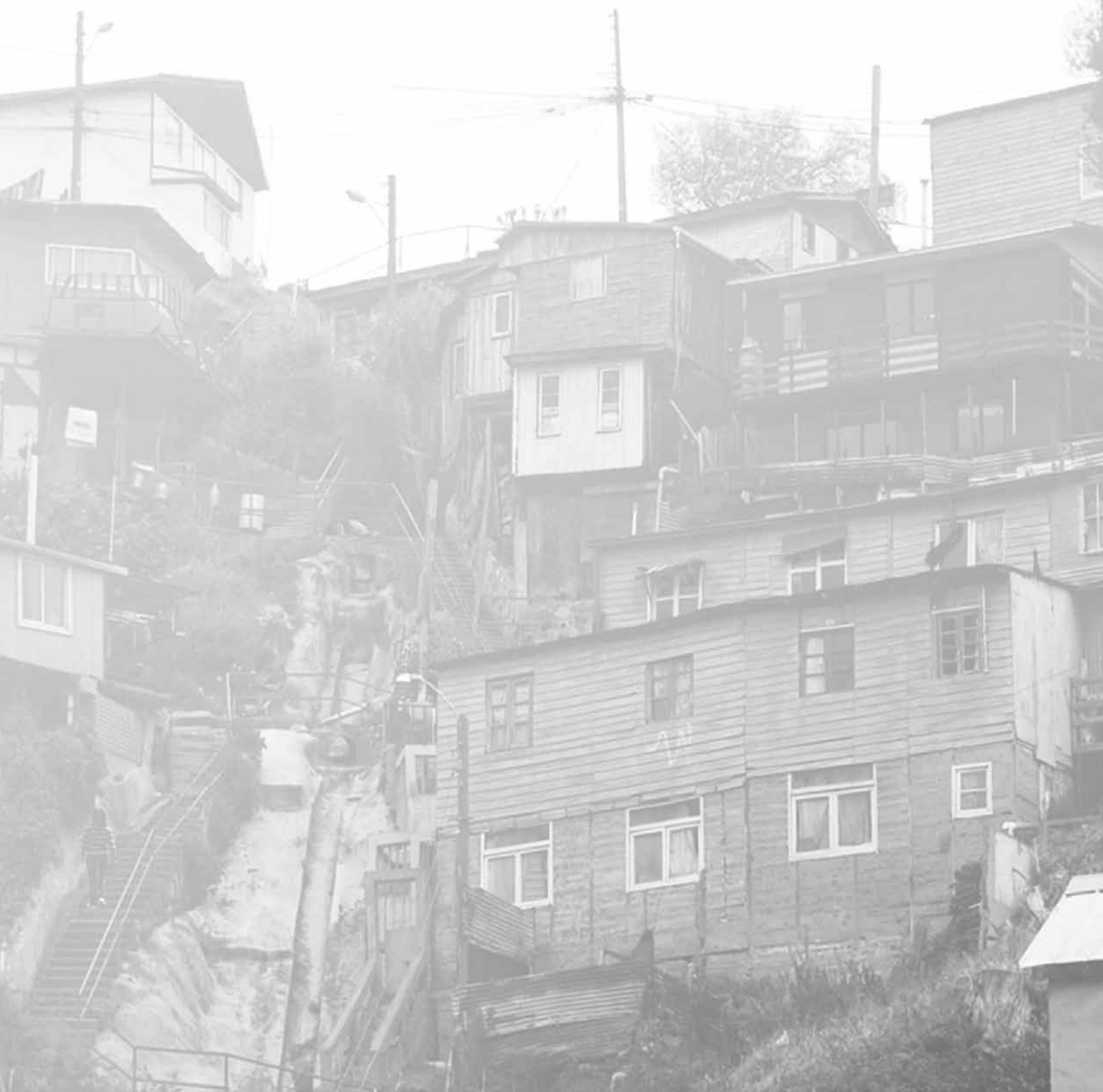

